\title{
El Control de Constitucionalidad en Latinoamérica: del control político a la aparición de los primeros Tribuna- les Constitucionales
}

Francisco Fernández Segado

\section{Consideraciones generales introductorias}

Como significaran Cabrera y Fix-Zamudio, ${ }^{1}$ siguiendo muy de cerca la idea vertida por Grant $^{2}$ en su ya clásica obra, si quisiéramos condensar en una frase la contribución de América a la defensa constitucional, podríamos decir que en este continente surgió la verdadera y propia garantía jurisdiccional de la Constitución, en contraste con el continente europeo, en donde se ensayó primeramente la búsqueda de una defensa política de la Constitución. ${ }^{3}$

Ello no obstante, no puede desconocerse que América Latina no iba a escapar al influjo europeo, y de modo muy específico, al impacto revolucionario francés. Bien al contrario, los países latinoamericanos se iban a afiliar desde muy temprano al denominado modelo político, que se copió de algunas constituciones francesas del período revolucionario. Es sabido que el modelo consistía en habilitar al congreso para llevar a cabo la custodia o salvaguarda de la Constitución, situación que se mantendría bastante tiempo, en algunos países, como es el caso de Chile,

1 Lucio Cabrera y Héctor Fix-Zamudio, en el «Prólogo» a la obra de James Allan Clifford Grant, "El control jurisdiccional de la constitucionalidad de las leyes" (Una contribución de las Américas a la Ciencia Política), México, Facultad de Derecho, Universidad Nacional Autónoma de México, 1963, p.10.

2 James Allan Clifford Grant, en su clásica obra citada en la nota inmediata anterior, cuyo subtítulo es harto significativo.

3 Cfr. al respecto, Roberto L. Blanco Valdés: "El valor de la Constitución” (Separación de poderes, supremacía de la ley y control de constitucionalidad en los orígenes del Estado liberal), Madrid, Alianza Editorial, 1994, en especial, pp. 249-307. 
Uruguay y el Perú, incluso hasta bien entrado el siglo actual.

En la cuarta década del pasado siglo la influencia norteamericana en este ámbito material se iba a hacer presente, implantándose paulatinamente en las constituciones iberoamericanas la judicial review, en acomodo con la tradición hispánica, la atracción ejercida por las cartas revolucionarias francesas y con el hecho condicionante de que el modelo norteamericano había de regir en un sistema jurídico bien alejado del de common law, como es el sistema romano-canonista. ${ }^{4}$

El principio común del control judicial de los actos de cualquier autoridad y de las propias disposiciones legales, en orden a la protección de los derechos constitucionales y demás normas de la Ley suprema no va a suponer una homogeneización de los procedimientos encaminados a la salvaguarda de la Constitución; bien al contrario, nos encontramos con diferencias fundamentales no ya sólo entre los Estados Unidos y los países latinoamericanos, sino, más ampliamente, entre estos últimos, que las más de las veces han seguido un camino propio, iniciándose solo en época reciente un intercambio e influencia recíprocos.

El transplante legal de la judicial review norteamericana, forjada, como antes dijimos, en la tradición jurídica del common law, a un trasfondo o marco hispánico y portugués de más de tres siglos, perteneciente al sistema romano-canónico, produjo, como significara Fix-Zamudio, ${ }^{5}$ instituciones peculiares que se apartan del modelo estadounidense, en cuanto se establecieron instrumentos procesales desarrollados en ordenamientos especiales, por lo que la propia revisión judicial se aplica a través de diversos procedimientos según los países, circunstancia que contrasta con el modelo norteamericano, en el que, como advierte Grant, ${ }^{6}$ la judicial review debe considerarse como un principio y no como una vía particular. ${ }^{7}$

Mientras un buen número de países latinoamericanos, México entre ellos, en sintonía con Estados Unidos, conceden a la Corte Suprema o a

4 Sobre esta mixtura y en relación con el juicio de amparo mexicano, cfr. Héctor FixZamudio: "The confluence of common law and continental european law in the mexican Writ of Amparo", en: The Mexican Forum, USA, Institute of Latin American Studies, The University of Texas at Austin, 1983, en especial, pp. 4-8.

5 Héctor Fix-Zamudio: «La Justicia Constitucional en América Latina», en: Lecturas Constitucionales Andinas, Núm. 1, Lima, Comisión Andina de Juristas, 1991, pp. 11 y ss.; en concreto, p. 19.

6 James Allan Clifford Grant: «El control jurisdiccional...», Op. Cit., pp. 34 y 39.

7 La regla básica del sistema norteamericano de control de constitucionalidad es que 
sus salas un aspecto limitado de jurisdicción original; otros países, como es el caso significativo de Colombia, Panamá y Cuba, ubicándose en el extremo opuesto, permiten, o lo han hecho en el pasado, que se pueda elevar directamente a la Corte Suprema cualquier problema constitucional que envuelva la validez de una ley. Se ha producido así, en algunos momentos históricos y en ciertos países, un auténtico monopolio por parte de la Corte Suprema de Justicia en el control de la constitucionalidad de los actos de autoridad. Y precisamente, a modo de dimanación de ese monopolio de la Corte Suprema, ha surgido en América Latina el primer Tribunal Constitucional, en Cuba, en la Constitución de 1940, aunque orgánicamente se nos presente como una sala especializada de la Corte Suprema de Justicia, bien que, a nuestro juicio, y como intentaremos mostrar más adelante, se trate de un auténtico Tribunal Constitucional.

Pese al precedente que acabamos de aludir, la influencia del llamado modelo austríaco-kelseniano de control de la constitucionalidad se hará sentir en mayor medida transcurridas dos décadas del final de la Segunda Gran Guerra, influencia que se intensificará de modo muy notable en los tres últimos lustros.

Sin embargo, la preponderante influencia del control jurisdiccional de tipo norteamericano ha propiciado que, en una suerte de variante del referido modelo austríaco, los ordenamientos iberoamericanos hayan conservado, simultánea o paralelamente, la facultad de los jueces ordinarios, o de algunos de ellos al menos, de decidir con efectos ordinarios, esto es, inter partes, sobre la constitucionalidad de las disposiciones legislativas en los casos concretos de que han de conocer, algo que está excluido en los ordenamientos europeos que cuentan con un Tribunal Constitucional.

Por todo ello, se ha podido hablar por Piza Escalante ${ }^{8}$ de una concepción iberoamericana «difuso-concentrada». Y García Belaunde, ${ }^{9}$ de

no hay un sistema especial para cuestiones constitucionales. Estas se deciden según surgen en cada caso determinado, cualquiera que sea la naturaleza de los derechos en cuestión, o de los recursos que se promueven. Dicho de otro modo, es un error buscar el sistema norteamericano en cualquier juicio, acción, auto, recurso u otro procedimiento. Ello no significa que el sistema carezca de unidad. Por el contrario, la unidad del sistema se encuentra en la teoría de que cualquier juez tiene el poder y el deber de aplicar las normas constitucionales por encima de cualquier otra regla y, por tanto, ha de considerarse nula y de ningún valor cualquier norma jurídica contraria a la Constitución. 
modo análogo, ha significado cómo el continente americano ha sido un campo fecundo para los diversos modelos de jurisdicción constitucional no sólo porque creó uno de ellos (el americano) y lo desarrolló ampliamente, sino porque a partir de este modelo ha avanzado muy lejos, anticipando el tardío modelo europeo y creando además dos categorías derivadas, pero no menos importantes: la mixta y la dual o paralela.

Hoy asistimos a una verdadera eclosión de los tribunales constitucionales en Latinoamérica, circunstancia que ha acentuado la pluralidad y heterogeneidad de modelos de control de constitucionalidad, generando fórmulas e instrumentos procesales en verdad sugestivos y originales, que en algunos casos, no en todos desafortunadamente, funcionan de modo muy satisfactorio. Bien es verdad que algunas concepciones constitucionales propias del más radical jacobinismo revolucionario francés, todavía presentes de una u otra forma, en el constitucionalismo latinoamericano, contribuyen a generar una serie de disfunciones altamente nocivas para la consolidación de un eficaz modelo de control de la constitucionalidad de las leyes y restantes normas de carácter general.

A los aspectos hasta aquí someramente esbozados nos referiremos en detalle a continuación.

\section{El control político de la constitucionalidad en Iberoamérica}

En pleno proceso revolucionario francés, Sieyés defendía la necesidad de crear un jurie constitutionnaire o Jury de Constitution, que de estas y otras formas se denominó. Para el diputado nacido en Fréjus en $1748,{ }^{10}$ la Constitución que la Convención Thermidoriana pretendía redactar requería de un Tribunal Constitucional, «esto es, un verdadero cuerpo de

8 Rodolfo Piza Escalante: «Legitimación democrática en la nueva Justicia Constitucional en Costa Rica», en: Anuario de Derecho Constitucional Latinoamericano, 1995, pp. 113 y ss.; en concreto, p. 155.

9 Domingo García Belaunde: "La acción de inconstitucionalidad en el Derecho comparadon, en: Lecturas Constitucionales Andinas, Lima, Comisión Andina de Juristas, Núm. 1, 1991, pp. 183 y si.; en concreto, p. 196.

10 Discurso pronunciado en la Convención del 2 de Thermidor del año III de la República (la intervención tiene lugar el 20 de julio de 1795). Puede verse en Enmanuel Sieyès. Escritos y Discursos de la Revolución (estudio preliminar, traducción y notas de Ramón Máiz), Madrid, CEC, 1990, pp. 251 y ss.; en concreto, p. 262. 
representantes con la misión especial de juzgar las reclamaciones contra todo incumplimiento de la Constitución». ${ }^{11}$

En esta misma línea de pensamiento ha de situarse la creación por la Constitución del año VIII (de 13 de diciembre de 1799) del llamado Sénat conservateur, al que se le asigna el control de todos los actos denunciados como inconstitucionales, ${ }^{12}$ figura que influiría claramente en varios ordenamientos constitucionales latinoamericanos del primer tercio del pasado siglo.

El propio Simón Bolívar, en su famoso Mensaje al Congreso Constituyente de Bolivia, fechado en Lima el 25 de mayo de $1826,{ }^{13}$ hizo alguna observación en torno a la necesidad de instaurar un sistema de control de la constitucionalidad de los actos del poder público. Y a tal efecto, pensó en un órgano encaminado a la salvaguarda de la Constitución, órgano que, bajo el rótulo de Cámara de Censores, se vertebraría como la tercera cámara del legislativo (en unión de la Cámara de Tribunos y de la Cámara de los Senadores). Serán éstos (los censores) -dirá Bolívar- ${ }^{1}$ «los fiscales contra el gobierno para celar si la Constitución y los tratados públicos se observan con religión».

La Constitución Política de Bolivia de $1826,{ }^{2}$ haciendo plenamente suya la idea bolivariana, acogía un Poder Legislativo tricameral una de cuyas cámaras, la llamada Cámara de Censores, asumía la facultad de «velar si el Gobierno cumple y hace cumplir la Constitución, las leyes y los tratados públicos", debiendo acusar ante el Senado las infracciones que el Ejecutivo hiciera de la Constitución, las leyes y los tratados públicos.

Aunque Urcullo ${ }^{16}$ considera que la Constitución boliviana de 1831 abre una nueva etapa en la que el control de constitucionalidad se

11 Al final de su intervención, Sieyès incluiría un pequeño texto articulado de cuatro preceptos, uno de los cuales, el cuarto, se refería al Tribunal Constitucional, propugnando la constitución bajo tal rótulo de un cuerpo de representantes en número equivalente a las $2 / 20$ de la legislatura, con la misión especial de juzgar y pronunciarse sobre las denuncias de violación de la Constitución dirigidas contar los decretos de la legislatura.

12 El Art. $21^{\circ}$ de la Constitución del año VIII (de 1799) disponía, en referencia al Senado conservador: "Il maintient ou annule tous les actes qui lui sont déférés comme inconstitutionnels par le Tribunat ou par le Gouvernement; les listes d'éligibles sont comprises parmi ces acts".

13 Simón Bolívar. Doctrina del Libertador, Venezuela, Biblioteca Ayacucho, Sucre, 1976, pp. 230-241.

14 Ibidem, p. 233.

15 Puede verse en Ciro Félix Trigo. Las Constituciones de Bolivia, Madrid, Instituto de Estudios Políticos, 1958, pp. 177 y ss. 
encomienda a un órgano especial, el Consejo de Estado, lo cierto es que, a nuestro juicio, esa nueva Constitución no quiebra la tendencia del control político iniciada en 1826, por cuanto que el Consejo de Estado era un órgano compuesto por siete consejeros nombrados por el Congreso de la República (uno por cada departamento de la nación), que venía obligado a informar documentalmente al Cuerpo Legislativo acerca de las infracciones a la Constitución. Es decir, se trataba de un órgano de naturaleza política que limitaba en este ámbito su función a informar al Legislativo de las violaciones constitucionales.

En definitiva, en esta primera etapa del constitucionalismo boliviano, que se prolonga hasta la Constitución de 21 de setiembre de 1851, que sentará las bases para un cambio de orientación, el control político de constitucionalidad, con una u otra característica, aparece profundamente arraigado, situación que bien puede considerarse como paradigmática, pues, ciertamente con notables alteraciones cronológicas en ocasiones, se repite en otros muchos países.

Es el caso, por ejemplo, de Costa Rica, cuya primera fase de su evolución constitucional, que se extiende a lo largo de medio siglo, desde la independencia (15 de setiembre de 1821) hasta la Constitución de 7 de diciembre de 1871 (período en el que Costa Rica conoció hasta once cartas constitucionales propias), viene caracterizada, en lo que ahora interesa, por un incipiente reconocimiento de la supremacía de la Constitución, una ficción de control de constitucionalidad retenido en el Poder legislativo, con ligeras y fracasadas incursiones en un control político delegado y en un control jurisdiccional consultivo. ${ }^{17}$

Brasil se acomoda asimismo a este arquetipo. Su primera norma suprema, la Constitución del Imperio de 1824, influida por el modelo francés, otorgó al Poder Legislativo la atribución no sólo de hacer las leyes, sino también las de interpretarlas, suspenderlas y revocarlas, así como la de velar por la salvaguardia de la Constitución. A juicio de Nogueira da Silva, ${ }^{18}$ el Código de 1824 se inspiró directamente en la

16 Jaime Urcullo Reyes. «El control constitucional en Bolivia antes de 1994. Legislación y jurisprudencia", en el colectivo: Una mirada a los Tribunales Constitucionales. Las experiencias recientes. Lecturas Constitucionales Andinas, Núm. 4), Lima, Comisión Andina de Juristas, 1995, pp. 39 y ss.; en concreto, pp. 44-46.

17 Rodolfo Piza Escalante. "Legitimación democrática en la nueva...», Op. Cit., pp. 151 152. 
doctrina de Benjamín Constant, a cuyo través se introdujo en Brasil la creencia de que a los jueces no debía serles permitido el adentrarse en la apreciación de la constitucionalidad de las leyes.

La Ley No 16, de 12 de agosto de 1834, que incorpora determinadas modificaciones y adiciones a la Constitución Política del Imperio, ${ }^{19}$ establecería un control preventivo de naturaleza política al facultar a los presidentes de las provincias a negarse a sancionar una ley cuando entendieren que violaba los derechos de otras provincias o los tratados internacionales; si la Asamblea provincial entendiese lo contrario por el voto de los dos tercios de sus miembros, el proyecto había de ser llevado a conocimiento del Gobierno y de la Asamblea General, que habrían de decidir con carácter definitivo. Este antecedente es bien significativo del modelo al que venimos refiriéndonos.

El régimen republicano inauguraría una nueva concepción en lo que atañe al control de la constitucionalidad. Según Ferreira, ${ }^{20}$ la influencia del Derecho norteamericano sobre algunas de las más notables personalidades de la época, como es el caso de Rui Barbosa, parece haber sido decisiva en orden a la consolidación del modelo de control difuso, que se introduciría en la llamada Constitución Provisional de 1890 y que la Constitución de la República de los Estados Unidos del Brasil, de 24 de febrero de 1891, consagraría definitivamente.

Ecuador se acomoda a una diacronía histórica análoga a la de los anteriores países. El modelo político será una realidad desde la primera Constitución de 1830 que ya otorgaba al Poder Legislativo la facultad de interpretar la Constitución en última instancia.

La Constitución ecuatoriana de 1851 creaba un Consejo de Estado al que encomendaba como primigenia atribución la de «velar sobre la observancia de la Constitución y de las leyes, dirigiendo al Poder Ejecutivo, bajo su responsabilidad, en caso de omisión, las reclamaciones correspondientes hasta por segunda vez, y dando cuenta a la Asamblea Nacional en su próxima reunión». El control se verificaba, pues, frente al Ejecutivo, reduciéndose en cualquier caso a reclamar ante el mismo y, caso de no

18 Paulo Napoleão Nogueira da Silva: "A evolução do controle da constitucionalidade e a competência do Senado Federal,, São Paulo, Editora Revista dos Tribunais, p. 18.

19 Puede verse en Themístocles B. Cavalcanti: «Las Constituciones de los Estados Unidos del Brasil", Madrid, Instituto de Estudios Políticos, 1958, pp. 307 y ss.

20 Gilmar Ferreira Mendes: "Controle de constitucionalidade» (Aspectos jurídicos e políticos), São Paulo, Editora Saraiva, 1990, pp. 170-171. 
ser atendida la reclamación, a dar cuenta de ello al Legislativo. Habría que esperar a la Constitución de 1869 para ver consagrado un control jurisdiccional de la constitucionalidad de carácter preventivo encomendado a la Corte Suprema.

Otros países han recepcionado mucho más tardíamente el control jurisdiccional de tipo norteamericano. Destacan al respecto los casos de Chile, Uruguay y el Perú. A ellos nos referimos finalmente.

En Chile, durante la dilatada vigencia de la Constitución de 1833 (1833-1924), como recuerda la doctrina, ${ }^{21}$ tanto los tribunales como la propia doctrina científica, estuvieron mayoritariamente de acuerdo en que la Corte Suprema carecía de atribuciones para llevar a cabo un control jurisdiccional de la constitucionalidad. Ello se sustentó, de un lado, en que los tribunales no poseian atribuciones expresas que autorizaran una actuación semejante, y de otro, en que el Art. $164^{\circ}$ de la citada Carta constitucional atribuía al Congreso la facultad de resolver las dudas que se produjeran sobre la inteligencia de alguno de los artículos de la propia Constitución.

La misma Corte Suprema, en un dictamen emitido el 6 de julio de 1848 , hacía suya la posición dominante, rechazando la posibilidad de que pudiese corresponderle llevar a cabo un control de constitucionalidad. ${ }^{22}$

En definitiva, en Chile, durante el pasado siglo y en el primer cuarto del actual, concretamente hasta la entrada en vigor de la Constitución de 1925, si bien existieron fallos discordantes, ${ }^{23}$ la realidad revela de modo inequívoco que la Corte Suprema rechazó seguir los pasos de la Suprema Corte norteamericana, lo que propició la consolidación de un control

21 Teodoro Ribera Neumann: «Función y composición del Tribunal Constitucional de Chile» (Constitución Política de 1980), en La Revista de Derecho, Chile, Facultad de Derecho, Universidad Central de Chile, año II, enero-junio 1988, pp. 37 y ss.; en concreto, p. 38.

22 Vale la pena recordar algunos argumentos de la Corte Suprema: «El Tribunal observará que ninguna magistratura goza de la prerrogativa de declarar la inconstitucionalidad de leyes promulgadas después del Código fundamental y de quitarles por este medio sus efectos y su fuerza obligatoria. Ese poder, que por su naturaleza será superior al legislador mismo, puesto que alcanzaba a anular sus resoluciones, no existe en magistratura alguna, según nuestro sistema constitucional. El juicio supremo del legislador, de que la ley que dicta no es opuesta a la Constitución, disipa toda duda en el particular y no permite retardos o demoras en el cumplimiento de sus disposiciones".

23 Raúl Bertelsen Repetto (en su obra Control de constitucionalidad de la Ley, Santiago, Editorial Jurídica de Chile, 1969, p. 136) se refiere a las Sentencias de 2 de enero de 1867 y de 1 de marzo de 1876). 
político de la constitucionalidad que se realiza por el propio Congreso Nacional y, durante su receso, por la llamada Comisión Conservadora. En el Uruguay, como advierte Gros Espiell, ${ }^{24}$ la historia de la jurisdicción constitucional puede dividirse en dos grandes períodos: antes y después del año 1934.

Hasta la entrada en vigor de la Constitución de 1934 no existía en el constitucionalismo uruguayo (Constitución de 1830, Ley de Reforma Constitucional de 1912, Constitución de 1918 y Leyes de Reforma Constitucionales de 1930 y 1932$)^{25}$ un sistema que regulara un procedimiento relativo a la declaración de inconstitucionalidad.

Las constituciones de 1830 y 1918 guardaron silencio al respecto, pese a que algún aislado precedente jurisprudencial y un excelente estudio monográfico de Jiménez de Aréchaga, habían sostenido la posibilidad de que los jueces pudieran declarar inaplicables, en una litis concreta, las normas eventualmente viciadas de inconstitucionalidad, lo que quizá hubiera podido propiciar un mayor debate al respecto en las Constituyentes de 1918. Sin embargo, como rotundamente señala Gros Espiell ${ }^{26}$ nunca la fórmula de la judicial review norteamericana se aceptó corrientemente en el Uruguay.

En las escasas ocasiones en que el tema se discutió bajo la vigencia de las dos constituciones antes citadas, se invocó como fundamento del rechazo, entre otros varios argumentos, tanto el necesario respeto al principio de división de poderes como, asimismo, la cláusula constitucional acogida en los dos códigos constitucionales de referencia (Art. $152^{\circ}$ de la Constitución de 1830 y Art. $176^{\circ}$ de la Constitución de 1918) que atribuía en exclusiva al Poder Legislativo la interpretación de la Constitución.

No obstante la tendencia generalizada a que acabamos de aludir, en 1874, como recuerda Korseniak, ${ }^{27}$ se dictaba una sentencia declarando la

24 Héctor Gros Espiell. "La Jurisdicción Constitucional en el Uruguay», en el colectivo, La Jurisdicción Constitucional en Iberoamérica, Bogotá, Universidad Externado de Colombia, 1984, pp. 71 y ss.; en concreto, p. 73.

25 Estos textos pueden verse en Héctor Gros Espiell: "Las Constituciones de Uruguay», $2^{a}$ de., Ediciones Cultura Hispánica del Centro Iberoamericano de Cooperación, Madrid, 1978 , pp. 205 y Sigs.

26 Héctor Gros Espiell. "La Jurisdicción Constitucional en el Uruguay", Op. Cit., p. 73. 
inconstitucionalidad y subsiguiente inaplicación de una ley de 1862, que lógicamente se entendía contraria a la Constitución de $1830 .^{28}$ Ello, ciertamente, no es sino la excepción confirmatoria de la ya apuntada regla general.

La situación cambiaría de forma radical con la Constitución de 1934, que dedicaría un capítulo específico a la declaración de inconstitucionalidad de las leyes, otorgando la competencia de la declaratoria de inconstitucionalidad a la Corte Suprema de Justicia.

En el Perú, la primera Constitución Política, sancionada en $1823,{ }^{29}$ hizo una clara enunciación de la supremacía de la Constitución sobre el resto del ordenamiento jurídico, bien que, curiosamente, como dice García Belaunde, ${ }^{30}$ aunque no tanto si advertimos el común denominador de los ordenamientos constitucionales de la época, encargó al órgano legislativo el control de las infracciones de la Constitución, sin crear al unísono un procedimiento especial al efecto.

Las constituciones que con posterioridad se sancionaron en el Perú, diez en total hasta la de 1979, exclusión hecha de ésta (constituciones de $1826,1828,1834,1836,1839,1856,1860,1867,1920$ y 1933), repitieron idéntico precepto, ubicándose, consecuentemente, en la dirección del control legislativo, esto es político, de la constitucionalidad.

Sólo la Carta de 1856, de vida fugaz, pues sólo estuvo vigente cuatro años, acogió un enunciado categórico que luego no se repitió en ninguna otra constitución y que pudo haber posibilitado la recepción judicial del control difuso. A tenor de su Art. $10^{\circ}$ : «Es nula y sin efecto cualquier ley en cuanto se oponga a la Constitución".

El transcrito precepto no fue acompañado de otro u otros que normaran el oportuno procedimiento, ni tampoco modificó el procedimiento de

27 José Korseniak. "La Justicia Constitucional en Uruguay», en: La Revista de Derecho, Facultad de Derecho, Universidad Central de Chile, año III, enero-junio 1989, pp. 105 y ss.; en concreto, p. 108.

28 La Ley de 1862 establecía que el Estado no tenía que indemnizar a los particulares por los daños que se les hubieran podido producir por perjuicios de guerra. La Sentencia entendió tal cláusula contraria a la Constitución, en uno de cuyos artículos se prevía que las requisas en caso de guerra originan el derecho de los particulares dañados a ser indemnizados.

29 Puede verse en Domingo García Belaunde. "Las Constituciones del Perú", Lima, Ministerio de Justicia (ed. Oficial), W. G. Editor; 1993, pp. 95 y ss.

30 Domingo García Belaunde. «El control de la constitucionalidad de las leyes en el Perú", en: Ius et Praxis (Revista de la Facultad de Derecho y Ciencias Políticas de la Universidad de Lima), Núm. 13. Lima, 1989, pp. 145 y ss.; en concreto, p. 146. 
control legislativo existente. Sin embargo, unos órganos jurisdiccionales menos apegados al texto escrito de la ley y más sensibles hacia el verdadero significado de la Constitución, hubieran podido dar vida al control judicial de la constitucionalidad a partir del referido precepto.

Es innecesario decir que el control de constitucionalidad por parte del órgano legislativo sería realmente ilusorio, pues es harto difícil que un órgano se controle a sí mismo. Sólo en 1945, como recuerda García Belaunde, ${ }^{31}$ el Congreso peruano, en forma ostensible, efectuó ese control de constitucionalidad al sancionar la Ley No 10334, derogando a la par de modo explícito la Ley No 8929 que había sancionado diversas reformas constitucionales con violación del procedimiento de reforma que la propia Constitución establecía.

El Perú será el país en el que más tardíamente se recepcionará normativamente el control difuso de la constitucionalidad de las leyes, pues habrá que esperar al Código Civil de 1936 para verlo introducido, por lo menos formalmente. En efecto, el Art. XXII del Título Preliminar del Código prescribirá: "Cuando hay incompatibilidad entre una disposición constitucional y una legal, se prefiere la primera".

Ello no obstante, cinco años antes, en 1931, la llamada «Comisión Villarán", por presidirla el notabilísimo constitucionalista peruano Manuel Vicente Villarán, a la que se había encargado por Resolución Suprema de 7 de agosto de 1931 la elaboración de un Anteproyecto de Constitución que había de ser sometido al Congreso Constituyente convocado para fines de ese mismo año, reivindicaba la conveniencia de constitucionalizar el control jurisdiccional de la constitucionalidad de las leyes, a cuyo efecto postularía la habilitación de los jueces y tribunales para, con ocasión de su conocimiento de cualesquiera clase de juicios, inaplicar las leyes que considerasen contrarias a la Constitución, en el bien entendido de que las sentencias de primera instancia que declararan que una ley se opone a la Constitución, habían de elevarse en consulta a la Corte Superior, si no existiere apelación en la forma ordinaria, correspondiendo definitivamente a la Corte Suprema, por el voto de los dos tercios de los miembros de la misma reunidos en Sala Plena, la declaración de inconstitucionalidad de una ley, declaratoria que había de regir tan sólo en el caso particular en que hubiere sido dictada. La Asamblea Constitu- 
yente, con gran estrechez de miras, desechó la propuesta formulada por la Comisión Villarán, optando una vez más por la añeja tradición peruana de encomendar al Congreso de la República el control político de la constitucionalidad.

Como antes señalábamos, el Código Civil de 1936 dió cauce normativo al control jurisdiccional de la constitucionalidad, pero la ausencia de disposiciones procesales que marcaran el camino a seguir en orden a la objetivación de ese control se tradujo en su nimia operatividad, por no decir, lisa y llanamente, en la nula vigencia del antes citado Art. XXII del Título Preliminar del Código.

Muchas objeciones fueron esgrimidas para volver inoperativo el control difuso. Y así, se adujo que la cláusula normativa de referencia se trataba de un enunciado de carácter general que no había sido debidamente reglamentado. También se esgrimió que se trataba de un principio de aplicación al estricto campo del derecho privado y no al del derecho público. Se opuso, finalmente, que el principio del control había sido contemplado por una ley que podía ser modificada por otra ulterior. Con todo ello, el principio fue desvalorizado e inutilizado, y no hubo otro remedio que esperai casi seis lustros, al Decreto Ley No 14605, de 25 de julio de 1963, Ley Orgánica del Poder Judicial, para ver procesalmente desarrollado el control difuso de constitucionalidad.

De esta forma, el hiperpositivismo de los jueces y tribunales del Perú, muy común por lo demás en casi toda Latinoamérica, la no contemplación de la Constitución como una norma jurídica, sino como un mero catálogo principal, de principios no estrictamente vinculantes en tanto no mediara su oportuno desarrollo, la endémica desconfianza hacia la Constitución y sus potenciales virtualidades transformadoras, patente progresivamente una vez que el constitucionalismo social del presente siglo se asienta, y una trasnochada e hiper-rígida visión del principio de división de poderes, entre los que el Congreso, con una inequívoca visión jacobina, sigue conservando, germinalmente al menos, todo el poder, imposibilitarán la constitucionalización del control jurisdiccional de constitucionalidad de las leyes en el Perú hasta la Carta Política de 1979.

La influencia de este modelo político de control de la constitucionalidad, soterradamente si se quiere, ha llegado hasta nuestros días con diversas manifestaciones, como es el caso de la atribución al Congreso de la República de la facultad de dictar leyes interpretativas de la Constitución (Art. 234 de la Constitución de Bolivia de 1967), o de la atribución al 
propio Congreso de la facultad de velar por el respeto de la Constitución (Art. 102.2 de la Constitución del Perú de 1993), facultades congresuales que no dejan de sorprender si se advierte que tanto en Bolivia, como en el Perú, se contempla constitucionalmente la figura de un Tribunal Constitucional que, en rigor, debe ser el único órgano constitucional encargado de velar por la salvaguarda de la Constitución y de interpretar la norma suprema del Estado. Consecuentemente, la atribución al Legislativo de facultades que pudieron tener su propia lógica en un modelo hoy ya periclitado no sólo no es de rigor en pura técnica constitucional, sino, lo que aún es peor, puede convertirse en un elemento notablemente disfuncional en cuanto germinador de graves conflictos entre órganos constitucionales del Estado.

\section{El control judicial de la constitucionalidad. Su recepción y difusión}

El modelo norteamericano de la revisión judicial, como ya indicamos en un momento anterior, iba a introducirse en los países latinoamericanos en fecha temprana, bien que la recepción de tal modelo no fuera ni una simple copia, ni una glosa servil del mismo, sino que, por el contrario, dio lugar a desarrollos de gran interés y con una indudable impronta propia.

El modelo de la judicial review fue conocido tanto por la difusión de los famosos textos reunidos bajo el rótulo The federalist papers, como, muy especialmente, por la rápida divulgación de la clásica obra de Alexis de Tocqueville, La democracia en América, ${ }^{32}$ cuya primera edición castellana, traducida por Sánchez de Bustamante, se publicó en París en 1836, un año después de la primera edición francesa y dos más tarde de la publicada en Inglaterra. ${ }^{33}$

Es opinión comúnmente admitida, como en su día se encargó de divulgar el gran tratadista norteamericano Eder ${ }^{34}$ gran conocedor de

32 Cfr. al efecto, Alexis de Tocqueville. La Democracia en América, capítulo sexto de la parte primera, referido al Poder Judicial en los Estados Unidos y a su acción sobre la sociedad política, Vol. $1^{\circ}, 1^{a}$ reimpr. de la $1^{a}$ ed., Madrid, Alianza, 1989, en especial, pp. $92-$ 97.

33 Cfr. al respecto, Héctor Fix-Zamudio. "A brief introduction to the Mexican Writ of Amparon, en: California Western International Law Journal, San Diego, primavera de 1979, p. 309. 
los temas latinoamericanos, que el primer documento constitucional que estableció la revisión judicial de la constitucionalidad de las leyes fue la Carta del Estado mexicano del Yucatán, de 16 de mayo de 1841, con apoyo en el Proyecto elaborado en diciembre de 1840 por una Comisión presidida por el ilustre jurista Manuel Crescencio Rejón, autor principal, si no único, del Proyecto y de la propia institución del amparo. ${ }^{35}$ Rejón diseñó los rasgos fundamentales del juicio de amparo, que se recogieron a nivel nacional en el Acta Constitutiva y de Reformas (de la Carta Federal de 1824) de 1847, de donde pasaron a la Constitución Federal de 1857, para llegar finalmente a la Constitución de Querétaro de 1917, hoy vigente como bien es sabido.

La revisión judicial se instrumentalizó a través del proceso de amparo ante la Corte Suprema de Justicia (Art. 62.I de la Constitución del Yucatán de 1841), funcionando, pues, como un régimen de control concentrado, si bien también se adoptó el modelo difuso en virtud de lo dispuesto en el Art. $75^{\circ}$ de la referida Constitución, que obligaba a los jueces a preferir la Constitución local sobre cualquier otra disposición legislativa en contrario, siendo en ello decisiva la voluntad expresada por Rejón de implantar la revisión judicial norteamericana, tal y como había sido divulgada por Tocqueville, que era expresamente citado en la Exposición de Motivos del Proyecto de 1840.

De esta forma, mientras el Art. $62^{\circ}$ de la constitución yucateca atribuía a la Corte Suprema de Justicia, como la primera de sus competencias, "amparar en el goce de sus derechos a los que le pidan su protección contra las leyes y decretos de la Legislatura que sean contrarios al texto literal de la Constitución», el Art. 8० facultaba a los jueces de primera instancia para amparar en el goce de los derechos a quienes les soliciten su protección contra cualquier funcionario que no pertenezca al orden judicial. Complementando ambas normas, el Art. $75^{\circ}$ de la carta yucateca ordenaba a los jueces que, en la administración de justicia, ajustasen sus

34 Phanor J. Eder. "Judicial Review in Latin America", en Ohio Law Journal, otoño de 1960 , pp. 572-573.

35 Ignacio Burgoa (en: El juicio de amparo, 20a ed., México, Editorial Porrúa, 1983, p. 115) destaca que Rejón juzgó conveniente la inserción en su Carta Política de varios preceptos que instituyeran diversas garantías individuales, si bien su mayor aportación fue la creación del medio controlador o conservador del régimen constitucional o «amparo», como él mismo lo llamó, ejercido por el Poder Judicial, con la ventaja de que tal control se extendía a todo acto (pato sensu) anticonstitucional. 
fallos a lo prevenido en la Constitución, prescindiendo de lo dispuesto contra su tenor literal en las leyes o decretos del Congreso del Estado.

El modelo del amparo mexicano se asentaría en la llamada «fórmula Otero", que implicaba que en las cuestiones constitucionales y de amparo, los tribunales de la Federación se habían de limitar «a impartir su protección en el caso particular sobre el cual versa el proceso, sin hacer ninguna declaración general de la ley o del acto que lo motivaren. ${ }^{36}$

Es posible que en el pensamiento de Mariano Otero influyera la desafortunada experiencia del Supremo Poder Conservador, órgano creado, a imagen del Senado Conservador francés, en la segunda ley constitucional de 1836, órgano de naturaleza política, integrado por cinco miembros, al que se facultaba para revisar, y en su caso anular, con efectos generales, los actos y normas de los distintos poderes del Estado dictados contra lo establecido en el ordenamiento constitucional. ${ }^{37}$

La ineficacia práctica y los conflictos que entre los tres poderes estatales generó la actuación de la citada institución, probablemente, condujeron a Mariano Otero a la enunciación de su "fórmula", cuyo objeto era imposibilitar al órgano encargado de llevar a cabo el control de constitucionalidad el hacer declaraciones generales de inconstitucionalidad.

La "fórmula Otero" se recogió en su literalidad en el Art. $25^{\circ}$ del Acta Constitutiva y de Reformas de 1847, siendo más tarde recepcionada por los constituyentes mexicanos de 1856-1857, quienes se inclinaron por el sistema de revisión judicial de las leyes que se incorporó dentro del juicio de amparo, dando así origen al «amparo mexicano contra leyes", única vía, hasta la reforma constitucional de diciembre de 1994, de atacar una norma legal por vicios de inconstitucionalidad.

De la lectura del voto particular de Otero y de la propia Exposición de Motivos del Proyecto de Constitución Federal de 1857 se desprende que al circunscribir las declaraciones de inconstitucionalidad

36 A tenor del Art. $19^{\circ}$ del Proyecto de Acta de reformas de Otero de 1847: «Los Tribunales de la Federación ampararán a cualquier habitante de la República en el ejercicio y conservación de los derechos que le concedan esta Constitución y las Leyes constitucionales, contra todo ataque de los poderes legislativo y ejecutivo, ya de la Federación, ya de los Estados, limitándose dichos Tribunales a impartir su protección en el caso particular sobre que verse el proceso, sin hacer ninguna declaración general respecto de la ley o del acto que lo motivare».

37 La segunda Ley constitucional de 1836 puede verse en José Barragán Barragán. Algunos documentos para el estudio del origen del juicio de amparo. 1812-1861. México, UNAM, 1987, pp. 162-168. 
al caso concreto, ${ }^{38}$ se trataba, entre otras cosas, de evitar los conflictos que podían surgir entre los poderes del Estado, y de modo más específico, de impedir la irrupción del juez en la escena política censurando al Legislativo.

Este modelo vendría a separarse, de facto, del modelo norteamericano. En efecto, conforme a la doctrina angloamericana del stare decisis, la decisión del más alto tribunal en cualquier jurisdicción es obligatoria para todos los tribunales inferiores de la misma jurisdicción, por lo que tan pronto el Tribunal Supremo declara una ley inconstitucional, ningún otro tribunal puede aplicarla.

En el mismo sentido, Grant ha podido afirmar ${ }^{39}$ que en los Estados Unidos una decisión definitiva del Tribunal Supremo por la que declara que una ley es inconstitucional tiene virtualmente el mismo efecto que la abrogación de la misma.

El principio del stare decisis no es, sin embargo, un principio recepcionado en los sistemas jurídicos romanistas, como es el caso de los latinoamericanos, donde los tribunales, generalmente, no están obligados por las decisiones de los órganos jurisdiccionales superiores. Así, en México, el precedente debía ser reiterado cinco veces en el mismo sentido para constituir jurisprudencia obligatoria.

Este principio de la desaplicación concreta de la ley, muy generalizado en Latinoamérica, especialmente con anterioridad a la aparición de los tribunales constitucionales, ha sido combatido por amplios sectores doctrinales. Entre la mejor doctrina, Carpizo y Fix-Zamudio, en defensa de la declaración general de inconstitucionalidad, han esgrimido, entre otros convincentes argumentos, los que siguen: ${ }^{40}$

a. Refuerza el principio de la igualdad de todos ante la ley y no permite que a quienes no solicitaron la protección jurisdiccional se les aplique la ley anticonstitucional, especialmente cuando estos últimos son

38 El Art. 101.I de la Constitución de 1857 atribuía a los tribunales de la federación la resolución de toda controversia que se suscite por leyes o actos de cualquier autoridad que violen las garantías individuales. Y el Art. $102^{\circ}$, en su inciso segundo, prescribía que: «La sentencia será siempre tal, que sólo se ocupe de individuos particulares, limitándose a protegerlos y ampararlos en el caso especial sobre que verse el proceso, sin hacer ninguna declaración general respecto de la ley o acto que la motivare».

39 James Allan Clifford Grant. «El control jurisdiccional de la constitucionalidad de las leyes", Op. Cit., p. 62.

40 Jorge Carpizo y Héctor Fix-Zamudio. «La necesidad y la legitimidad de la revisión judicial en América Latina. Desarrollo reciente», en: Boletín Mexicano de Derecho Comparado, Núm. 52, enero-abril 1985, pp. 31 y ss.; en concreto, p. 54. 
miembros de los sectores más débiles, social, cultural y económicamente, de la sociedad.

b. La fórmula de la desaplicación de la norma inconstitucional, con los subsiguientes efectos inter partes, al operar en un marco en el que, de un lado, no existe la fuerza del precedente, y de otro, por lo general, los órganos jurisdiccionales se hallan muy recargados de asuntos, puede propiciar la inoperancia del sistema al existir el peligro de colapsarlo. c. La declaración general de inconstitucionalidad refuerza la cohesión jurídica y social que la Constitución persigue, al impedir la aplicación de leyes y normas reglamentarias consideradas inconstitucionales por el máximo tribunal de un país.

Como ya advertimos, en el constitucionalismo de nuestro tiempo tiende a expandirse la fórmula de la declaratoria general de inconstitucionalidad, con efectos, en consecuencia, erga omnes, si bien, según los países, nos encontramos con modelos muy diversos, en algunos de los cuales conviven la declaratoria general con la desaplicación en el caso concreto.

En México, como hemos expuesto, antes del término de la primera mitad de la pasada centuria, quedaba institucionalizado a nivel federal el control judicial de constitucionalidad, y es opinión casi unánime que México es el primer país donde es recepcionado el modelo norteamericano. Siendo en puridad ello así, no podemos, sin embargo, ignorar la existencia de algunos antecedentes que no tuvieron continuidad, ni tan siquiera en algún caso, vigencia real y efectiva, pero que son bien expresivos del interés que desde los mismos albores de la Independencia despertó en América Latina el control difuso de la constitucionalidad surgido en los Estados Unidos.

El primero de estos antecedentes es el de la Constitución de Venezuela de 1811 , cuyo Art. $227^{\circ}$ estableció una cláusula de supremacía análoga a la acogida en la Constitución norteamericana de 1787. A su tenor:

"La presente Constitución, las leyes que en consecuencia se expidan para ejecutarla y todos los tratados que se concluyan bajo la autoridad del Gobierno de la Unión serán la ley suprema del Estado en toda la extensión de la Confederación, y las autoridades y habitantes de las provincias estarán obligados a obedecerlas y observarlas religiosamente sin excusa ni pretexto alguno; pero las leyes que se expidieren contra el tenor de ella no tendrán ningún valor, 
sino cuando hubieren llenado las condiciones requeridas para una justa y legítima revisión y sanción».

La cláusula en cuestión no sólo establecía la garantía de la supremacía constitucional, sino su consecuencia inmediata, esto es, la nulidad de toda ley que contradijera las determinaciones constitucionales.

A la vista del precepto transcrito, bien puede decirse con Ayala ${ }^{41}$ que desde 1811 los jueces venezolanos se hallaban facultados para declarar la nulidad de las leyes inconstitucionales, bien que no puede olvidarse que la Carta de 1811 apenas si tuvo vigencia efectiva. En apoyo de la posición doctrinal precedentemente citada, quizá quepa aducir que el Poder Judicial de la Confederación era habilitado por el Art. $115^{\circ}$ de la Constitución para conocer «de todos los asuntos contenciosos civiles o criminales que se deriven del contenido de esta Constitución», asumiendo la Corte Suprema (en el Art. 116 $)$ competencias por apelación. En una dirección similar, La Roche ${ }^{42}$ ha considerado que con la Carta de 1811 se inicia un período de "control implícito" de la constitucionalidad por parte de los jueces, que va desde 1811 hasta 1858, cuando la Constitución de este último año eleve al máximo rango normativo la acción popular de inconstitucionalidad.

Bien es cierto que la Carta Política de 1811, paralelamente, y en perfecta sintonía con lo que, como hemos visto, sería pauta general de la primera fase del constitucionalismo latinoamericano, estableció un sistema de control político de la constitucionalidad de las leyes provinciales, por cuya virtud el Congreso era habilitado para verificar un control previo de las mismas, circunstancia que se ha justificado ${ }^{43}$ por los propios antecedentes históricos que mostraban una activa vida provincial.

Tras la batalla de Carabobo, el Congreso General de Colombia, reunido en Cúcuta, ratificaba la que sería la Constitución de 1821 de los Pueblos de la Gran Colombia, que agrupaba a Venezuela, Cundinamarca

41 Carlos M. Ayala Corao. "Algunas consideraciones sobre la jurisdicción constitucional en Venezuelan, en el colectivo, Una mirada a los tribunales constitucionales. Las experiencias recientes (Lecturas constitucionales Andinas, Núm. 4), Lima, Comisión Andina de Juristas, 1995, pp. 241 y ss.; en concreto, p. 242.

42 Humberto La Roche. Instituciones constitucionales del Estado venezolano, Maracaibo, 1984. Cit. por Carlos M. Ayala Corao: "Algunas consideraciones...», Op. Cit., p. 242.

43 Tomás Polanco. «El recurso de inconstitucionalidad en la Constitución Venezolana de 1811 \%, en el colectivo, Las formas jurídicas en la Independencia, Caracas, Instituto de Estudios Políticos, Universidad Central de Venezuela, 1962, pp. 82-83. 
y Quito, esto es, los pueblos del antiguo Virreinato de la Nueva Granada y de la Capitanía General de Venezuela. ${ }^{44}$ Aunque la Constitución (en su Art. $188^{\circ}$ ) proclamó su primacía, sin embargo, abandonó todo atisbo de control jurisdiccional de constitucionalidad, facultando al Congreso (en su Art. 189 ) para resolver cualquier duda «sobre la inteligencia de algunos artículos de esta constitución». Consecuentemente, el control judicial posibilitado, de modo implícito al menos, por la Constitución de 1811 no tuvo continuidad, ${ }^{45}$ ni tan siquiera existencia real, pues la propia Constitución no la tuvo.

Guatemala es el otro país que nos ofrece un antecedente del control judicial, un tanto irregular desde luego, y con una vigencia muy delimitada temporalmente, pero no por ello menos singular.

Aunque, como señala García Laguardia, ${ }^{46}$ la fuente norteamericana aparece muy clara en el primer constituyente federal centroamericano, lo cierto es que la Constitución Federal de la República de Centro-América de 22 de noviembre de $1824^{47}$ no contempló el control judicial de la constitucionalidad de las leyes. Las Reformas a esa Constitución -de 1835sí acogerían una cláusula muy similar a la cláusula de supremacía norteamericana ${ }^{48}$ norma que pronto iba a incidir, a nivel legislativo ordinario en alguno de los Estados integrantes de la Federación.

En efecto, la Asamblea Legislativa del Estado de Guatemala, la más importante de la Federación, promulgaba el 13 de setiembre de 1837 la «Declaración de los derechos y garantías que pertenecen a todos los ciu-

44 Puede verse el texto de la Constitución de 1821 en: Allan R. Brewer-Carfas. Las Constituciones de Venezuela, Venezuela-Madrid, Universidad Católica del Táchira-IEAL-CEC, San Cristóbal, 1985, pp. 273 y ss.

45 Como advierte Andueza, la Constitución venezolana de 1830, primera del Estado autónomo de Venezuela tras la separación de Colombia, acogió un criterio político de control de la constitucionalidad, al atribuir al Congreso la función de interpretar la Constitución, y a la Cámara de Representantes la de "velar por el exacto cumplimiento" de la Constitución y las leyes. José Guillermo Andueza Acuña. La jurisdicción constitucional en el Derecho Venezolano, Caracas, Universidad Central de Venezuela, 1974, p. 32.

46 Jorge Mario García Laguardia. La defensa de la Constitución, Guatemala-México, Facultad de Ciencias Jurídicas y Sociales de la Universidad de San Carlos de Guatemala Instituto de Investigaciones Jurídicas de la UNAM, 1986, p. 52.

47 Su texto puede verse en Ricardo Gallardo. Las Constituciones de la República Federal de Centro-América, Vol. II, Madrid, Instituto de Estudios Políticos, 1958, pp. 703 y ss.

48 A tenor del Art. 189 , tras la redacción que se le diera en 1835: “Esta Constitución y las leyes federales que se hagan en virtud de ella; y todos los tratados, hechos o que se 
dadanos habitantes del Estado de Guatemala", a tenor de cuyo Art. 5o:

"Que toda determinación sea en forma de ley, decreto, providencia, sentencia, auto $u$ orden que proceda de cualquier poder, si ataca alguno o algunos de los derechos naturales del hombre, o de la comunidad, o cualquiera de las garantías consignadas en la ley fundamental, es ipso iure nula, y ninguno tiene obligación de acatarla y obedecerla».

Un año más tarde, en 1838, la misma Asamblea Legislativa promulgaba un Decreto de cuatro artículos que venía a desarrollar ese principio de la supremacía constitucional. Su norma de apertura proclamaba que ninguna ley contraria a la Constitución puede ni debe subsistir. Y en coherencia con ello, el Art. $2^{\circ}$ disponía que cuando se presente alguna notoriamente contraria a la Constitución, «los tribunales deberán arreglarse en sus juicios al sentido claro de lo fundamental, informando en seguida al cuerpo legislativon. Cuando se presentaren casos dudosos, «los tribunales y cualquier ciudadano pueden pedir a la Asamblea la declaratoria correspondiente, sin perjuicio de que dichos tribunales resuelvan desde luego, según entiendan en justicia, y por su propio convencimiento».

Como puede apreciarse, Guatemala instauraba a través de estas normas un control jurisdiccional de la constitucionalidad, matizado por la intervención del cuerpo legislativo, control que se vinculaba íntimamente a la salvaguarda de los derechos fundamentales.

La experiencia fue fugaz, pues a la caída del régimen liberal, coincidente con la quiebra de la Federación, la idea fue abandonada. Como señala García Laguardia, ${ }^{49}$ los gobiernos de la restauración conservadora desconfiaban de la revisión judicial, lo que explica que se expidiera de inmediato el Decreto de 27 de setiembre de 1845, cuyo Art. $1^{\circ}$, tajantemente, determina que: «Ningún acto del Poder Legislativo ni Ejecu-

hicieren bajo la autoridad federal, serán la suprema ley de la república, y los jueces en cada uno de los Estados, están obligados a determinar por ellas, no obstante cualesquiera leyes, decretos u órdenes que haya en contrario en cualquiera de los Estados».

49 Jorge Mario García Laguardia: «La Corte de Constitucionalidad (Tribunal Constitucional) de Guatemala. Orígenes y competencias", en: Cuadernos Constitucionales MéxicoCentroamérica, Núm. 8, México, Instituto de la República de Guatemala, 1994, pp. 29 y ss.; en concreto, p. 32. 
tivo está sujeto a revisión de los tribunales de justicia, los cuales no pueden conocer de la nulidad o injusticia que aquéllos contengan».

La recepción del modelo de la revisión judicial norteamericana en México y alguno de los antecedentes de la misma a que acabamos en aludir (el caso de Guatemala) ya muestran, aunque larvadamente, un rasgo diferencial del que queremos hacernos eco ahora.

La judicial review norteamericana no puede desvincularse del modelo federal de Estado acogido por los constituyentes de 1787, mientras que el control judicial de la constitucionalidad en Latinoamérica se vincula de modo estrecho con la protección de los derechos y libertades constitucionales. Reflexionaremos algo más torno a esta idea.

Quizá no sea inoportuno recordar que durante la campaña de ratificación de la Constitución Federal de 1787, los antifederalistas esgrimieron contra el perfil constitucional del Poder Judicial el argumento de que el mismo estaba concebido como un instrumento de centralización frente a los Estados miembros de la Unión; no era ajena a ello la idea de que, en su inicio, la judicial review parecía pensada tan sólo frente a las leyes de las legislaturas de los Estados de la Unión. En tal situación, y a fin de rebatir ese argumento, Hamilton objetivaba en su artículo LXXVIII de El Federalista ${ }^{50}$ la función del Poder Judicial, extendiendo la judicial review a las leyes no sólo de las legislaturas estatales, sino también a las emanadas del Congreso de la Unión. Con tal postura, Hamilton matizaba la posición que cuatro meses antes había sostenido en el artículo XXXIII de la propia obra.

Ciertamente, en América Latina, también ciertos institutos procesales orientados a la salvaguarda de la primacía constitucional iban a encontrar su razón de ser, por lo menos en un primer momento, en la estructura federal del Estado, cual es, por ejemplo, el caso de la acción popular de inconstitucionalidad en Venezuela; sin embargo, la recepción del control judicial de la constitucionalidad encuentra su última y más convincente ratio en la tutela de los derechos constitucionales. La preocupación por esta cuestión estuvo bien presente ya en algunos diputados americanos de las Cortes de Cádiz, y no es casual el que sea en Guatemala donde hallamos el antecedente más consistente de la ulterior recepción definitiva de la judicial review en el Yucatán, como tampoco lo es que la recepción del

50 A. Hamilton, J. Madison y J. Jay. El Federalista, México, Fondo de Cultura Económica, $1^{\text {a }}$ reimpr. de la $2^{\mathrm{a}}$ de., 1974 . El artículo LXXVIII puede verse en pp. 330-336. 
instituto en Guatemala se enmarque en la búsqueda de instrumentos eficaces de protección de los derechos frente a las actuaciones inconstitucionales de cualesquiera poderes del Estado.

El rasgo diferencial que advertimos no hace sino corroborar el dato incontrastable de que, por lo general, ningún modelo jurídico se apega al modelo original, sino que, a partir del mismo, se lleva a cabo un diseño que no es sino una adaptación a las propias realidades políticas, sociales y culturales, surgiendo de esta forma, y de modo progresivo, modelos derivados.

Esta reflexión es plenamente aplicable a la recepción de la judicial review en América Latina. Incluso en la Argentina, el país que más de cerca ha seguido el modelo norteamericano, nos encontramos con unos rasgos peculiares que dan al modelo una cierta originalidad frente al tipo original.

En efecto, en la Argentina, si bien todos los jueces están habilitados para ejercer el control de constitucionalidad de las leyes que han de aplicar en un caso litigioso del que conocen, nos encontramos con una vía para derivar dicho control a la Corte Suprema de Justicia, mediante el ejercicio del «recurso extraordinario de inconstitucionalidad», vía excepcional que, como advierte Bidart, ${ }^{51}$ difiere de la jurisdicción apelada ordinaria de la propia Corte, pues mediante tal recurso no se provoca una tercera instancia común de revisión, sino una revisión constitucional.

Asimismo, a nivel federal, existe lo que se conoce como la «acción declarativa de certeza", que aun no pudiendo considerarse como una acción de inconstitucionalidad pura, pues ésta es improcedente en el orden federal argentino, posibilita un control constitucional y la eventual declaración de inconstitucionalidad.

Todo ello marca una diferencia con el modelo norteamericano, a la que hay que añadir la producida como consecuencia de la ausencia en el ordenamiento argentino de un remedio legal semejante a la injunction inglesa, ausencia que, como señalara Grant, ${ }^{52}$ mermaba notablemente la protección de los derechos individuales, y que fue suplida por la creación jurisprudencial del amparo, a raíz de la Sentencia de 27 de diciembre de

51 Germán Bidart Campos. «La jurisdicción constitucional en Argentina», en el colectivo, La jurisdicción constitucional en Iberoamérica (II Coloquio Iberoamericano de Derecho Constitucional), Bogotá, Universidad Externado de Colombia, 1984, pp. 271 y ss.; en concreto. p. 283. 
1957, dictada por la Corte Suprema de Justicia de la Nación en el Caso Angel Siri, a la que seguiría el año siguiente la no menos conocida Sentencia dictada en el Caso Samuel Kot.

Uno de los procesos constitucionales más peculiares y sugestivos de América Latina es el de la acción popular de inconstitucionalidad, instituto que se ha de ubicar dentro del control judicial de la constitucionalidad.

Sus precedentes se remontan a la Constitución de Cundinamarca, de 4 de abril de 1811, considerada por un amplio sector doctrinal como la primera constitución colombiana, ${ }^{53}$ que estableció un control de constitucionalidad por vía de acción directa, abierta y pública de los ciudadanos, contra todo acto jurídico atentatorio contra la Constitución.

La conformación de este instituto procesal constitucional quizá refleja la propia mixtura de principios del constitucionalismo norteamericano y principios informantes de la Constitución francesa del Directorio que, a juicio de Uribe, ${ }^{54}$ caracteriza la temprana Constitución de 1811 , anterior a la de Cádiz.

En efecto, la citada Carta de 1811 creaba un llamado «Senado de censura y protección", compuesto de un presidente (que lo será el vicepresidente de la Representación Nacional) y cuatro miembros, órgano al que se le atribuye la función de «sostener esta Constitución y los derechos del pueblo, a fin de que, de oficio o requerido por cualquier ciudadano, reclame cualquier infracción o usurpación de todos o cada uno de los tres Poderes Ejecutivo, Legislativo y Judicial que sea contra el tenor de la Constitución" (Art. $9^{\circ}$ del Título I). Este "Senado de censura y protección» podía parecer un órgano político, pero, a juicio de Restrepo, ${ }^{55}$ no lo era por cuanto ocupaba el primer lugar en la jerarquía del Poder Judicial. El Art. $3^{\circ}$ del Tírulo VII, relativo al Poder Judicial, prescribía que: «el primer Tribunal de la provincia preferente a todos los demás es el Senado", cuyo objetivo primigenio, a tenor del Art. $4^{\circ}$ del propio Título,

52 James Allan Clifford Grant: «El control jurisdiccional de la constitucionalidad de las leyes", Op. Cit., pp. 51-52.

53 No faltan quienes consideran como primer código constitucional colombiano la Constitución del Estado Libre e Independiente del Socorro, suscrita el 15 de agosto de 1810 . Cfr. al efecto, Horacio Rodríguez Plata. La antigua Provincia del Socorro y la Independencia. Bogotá, Biblioteca de Historia Nacional, vol. XCVIII, 1963, p. 50.

54 Diego Uribe Vargas. Las Constituciones de Colombia, vol. I, $2^{\text {a }}$ ed., Madrid, Ediciones Cultura Hispánica, 1985, p. 64.

55 Carlos Restrepo Piedrahita. Tres ideas constitucionales, Bogotá, Universidad Externado de Colombia, 1988, p. 15. 
era «velar sobre el cumplimiento exacto de esta Constitución e impedir que se atropellen los derechos imprescriptibles del pueblo y del ciudadanom..$^{56}$

En definitiva, la Carta de 1811 venía a caracterizar el control de constitucionalidad por estos rasgos básicos:

$1{ }^{\circ}$ Concentración en un solo órgano, el "Senado de censura y protección», órgano situado en la cúspide del Poder Judicial de la Provincia, aunque con visos indudablemente políticos, de la función de salvaguardar la Constitución frente a cualquier acto violatorio procedente de un poder público.

$2^{\circ}$ Habilitación a cada ciudadano, con independencia de que ostentara $o$ no un interés subjetivo, para denunciar ante el Senado de censura las infracciones de la Constitución en que incurrieran funcionarios de cualquiera de los tres poderes del Estado, lo que suponía la conformación de una auténtica acción popular.

$3^{\circ}$ Atribución al Poder Ejecutivo de la competencia de objetar ante el órgano en cuestión los proyectos de leyes aprobados por el Legislativo, tanto por vicios materiales como por defectos formales en el procedimiento de su tramitación.

La acción popular seguiría siendo contemplada por la segunda Constitución de Cundinamarca, de 1812, que, sin embargo, se incardinaría de lleno en el modelo de control político de la constitucionalidad, al habilitar a la primera Cámara de la Legislatura, el Senado, como «conservadora de la Constitución", habiendo, pues, de conocer tal Cámara de todas las quejas presentadas por los ciudadanos por supuestas violaciones constitucionales. La vertiente jurisdiccional de la acción popular se había ya perdido y tardaría bastantes lustros en reverdecer.

La reaparición de la acción popular se produce casi medio siglo después, bien que en el plano legislativo no constitucional.

La Ley Orgánica de la Administración y Régimen Municipal, de 22 de junio de 1850, encargaba a la Suprema Corte de Justicia de Colombia el conocimiento de las causas directas, abiertas y ciudadanas contra las 
normas de las cámaras provinciales y de los cabildos parroquiales, por razones de inconstitucionalidad. Los efectos del fallo declaratorio de la inconstitucionalidad se proyectaban erga omnes, pues lo que se solicitaba era la anulación de la norma inconstitucional, no su mera inaplicación. Ortiz $^{57}$ destaca la similitud material y proximidad temporal entre el modelo acuñado en Colombia en 1850 y el institucionalizado en Suiza en 1848, al amparo de la Constitución de ese año, que posibilitó que los ciudadanos pudieran presentar recursos de inconstitucionalidad contra las leyes de los cantones, mecanismo procesal constitucional que se mantenía en la Constitución de 1874.

Esta acción popular no sería constitucionalizada sino hasta 1910. La carta política para la confederación granadina del año 1858 dio un primer paso en el sentido de limitar la acción conjunta de los poderes Legislativo y Ejecutivo en el ámbito estatal, no nacional. En tal sentido, su Art. 50 otorgó a la Corte Suprema de Justicia una facultad suspensiva de la ejecución de los actos de las legislaturas de los Estados, "en cuanto sean contrarios a la Constitución o a las leyes de la Confederación", tras lo que la Corte Suprema había de dar cuenta al Senado a fin de que éste decidiera definitivamente sobre la validez o nulidad de dichos actos.

La Constitución de la República de Colombia, de 4 de agosto de 1886, que ha permanecido vigente algo más de un siglo, optó por un modelo de control de constitucionalidad que Miguel Antonio Caro, su redactor denominó el "plan de veto".

Previamente, el propio Caro había redactado un artículo en la más pura tradición norteamericana, de acuerdo con el cual los estatutos o leyes contrarias a la Constitución serían nulos y, consecuentemente, no tendrían validez en los tribunales. Sin embargo, en un segundo momento, el propio Caro optó por el citado "plan de veto», un segundo y bien diferenciado método de control en el que éste se vincula al enfrentamiento entre el Legislativo y el ejecutivo con ocasión de la tramitación de un proyecto de ley. De acuerdo con este modelo de control, si un acto del Congreso es vetado por inconstitucional, en todo o en parte, por el Presidente y tal veto es sobrepasado, entonces el acto legislativo en cuestión ha de ser remitido a la Corte Suprema de Justicia para que, en el

57 Julio César Ortiz: «El sistema de control constitucional en Colombia», en: Boletín mexicano de Derecho Comparado, año XXIV, Núm. 71, mayo-agosto 1991, pp. 481 y ss.; en concreto, pp. 492-493. 
plazo de seis días, decida sobre su exequibilidad. El fallo afirmativo de la Corte obligaba al Presidente a la sanción de la ley. Si fuere negativo, esto es, si la Corte se mostraba contraria a la exequibilidad, el proyecto de ley debía ser archivado.

El "plan de veto» de Caro no era en realidad una fórmula original, pues ya la Constitución ecuatoriana de 1869 lo había establecido en términos muy similares, pasando de ahí a la Constitución ecuatoriana de 1878 que lo contempló con mayor claridad aún. ${ }^{58}$

Por lo demás, el control de constitucionalidad desencadenado por un veto presidencial a un proyecto de ley en trámite en el Congreso o aprobado ya por el mismo, por razones de supuesta inconstitucionalidad, ha sido desde lejos muy común en los países iberoamericanos, en donde este control preventivo ha sido ampliamente recepcionado. Pensemos, por poner un ejemplo tan sólo, que el Tribunal Constitucional chileno fue creado precisamente como órgano de resolución de los conflictos que enfrentaban al Congreso y al presidente con ocasión de la tramitación de los proyectos de leyes.

A principios de siglo iba a gestarse un proceso que habría de culminar en la constitucionalización en Colombia de la acción popular. Con fundamento en el Acto Legislativo $\mathrm{N}^{\circ}$ 9, de 1905, era convocada una Asamblea Nacional que llevaba a cabo en 1910 la revisión de la Constitución. La Asamblea Nacional de Colombia, a través del Acto Legislativo $\mathrm{N}^{\circ} 3$, de 31 de octubre de $1910,{ }^{59}$ procedía a una profunda reforma constitucional que, en lo que ahora interesa y según Restrepo ${ }^{60}$ venía a culminar todo el proceso de noventa y nueve años abierto con la Constitución de la provincia de Cundinamarca de 1811, y orientado a la afirmación constitucional explícita del principio de supremacía constitucional, íntimamente unido al establecimiento del sistema de control jurisdiccional de la constitucionalidad.

El Art. $40^{\circ}$ del Título XV, tras la reforma, prescribía de modo rotundo: «en todo caso de incompatibilidad entre la Constitución y la ley se aplicarán de preferencia las disposiciones constitucionales». Y el precepto

58 Cfr. al efecto, Hernán Salgado Pesantes: «El control de constitucionalidad en la Carta Política del Ecuador", en el colectivo, Una mirada a los Tribunales Constitucionales. Las experiencias recientes, $O$ p. Cit, pp. 167 y ss.;en concreto, pp. 168-169.

59 Puede verse en Diego Uribe Vargas. Las Constituciones de Colombia, Op. Cit, vol. III, pp. 1193 y ss.

60 Carlos Restrepo Piedrahita. Tres ideas constitucionales, Op. Cit, p. 55. 
inmediatamente ulterior disponía: «A la Corte Suprema de Justicia se le confía la guarda de la integridad de la Constitución. En consecuencia, además de las facultades que le confieren ésta y las leyes, tendrá la siguiente: decidir definitivamente sobre la exequibilidad de los Actos legislativos que hayan sido objetados como inconstitucionales por el Gobierno, o sobre todas las leyes o decretos acusados ante ella por cualquier ciudadano como inconstitucionales, previa audiencia del Procurador General de la Nación".

El modelo colombiano, siempre bajo la vigencia de la Carta de 1886, fue modificado en distintos momentos, como en 1945, 1960 y 1968, pero, en su esencia, continuó caracterizado por ser un control jurisdiccional que, según los casos, se encomendaba a la Corte Suprema de Justicia, al Consejo de Estado y a todos los jueces de la República, y por abarcar de forma integral todos los actos del Estado.

Con todo, su rasgo más peculiar, e incluso su instituto procesal constitucional más relevante, es la acción popular (que, según los supuestos, se conoce como pública o ciudadana), que habilita a todo ciudadano para acusar ante la Corte Suprema de Justicia, por la vía principal de acción pública, directa o abierta, y sin necesidad de demostrar interés alguno o de estar vinculado a un proceso, cualquier ley o decreto con fuerza de ley que estime contraria a la Constitución.

En definitiva, tras la reforma constitucional de 1910, la Corte Suprema de Justicia canalizó su función de «guarda de la integridad de la Constitución" por intermedio de su facultad de decidir de modo definitivo sobre la constitucionalidad de los proyectos de ley (pues la Corte seguía conservando la facultad que le atribuyera la Carta de 1886 en su redacción inicial), así como a través de su facultad de pronunciarse sobre la constitucionalidad de todas las leyes del Congreso, pronunciamiento en el que la acción ciudadana desempeñaba un rol esencial. Las decisiones de la Corte Suprema tenían efectos definitivos, esto es, fuerza de "cosa juzgada», efectos que se proyectaban erga omnes cuando el pronunciamiento se verificaba por vía principal.

Junto a la Corte, el Consejo de Estado desempeñaría un importante papel en el control de la constitucionalidad de los decretos gubernamentales, que podía ser instado asimismo por acción popular.

La acción popular no es un procedimiento exclusivo de Colombia, sino que es un instituto que, coetáneamente, fue recepcionado en Venezuela. La Constitución venezolana de 24 de diciembre de 1858 es, en 
puridad, la primera norma constitucional que consagra la acción popular, que ocho años antes había tenido acogida legislativa en Colombia.

La constitucionalización de la acción popular en Venezuela tiene mucho que ver con la conformación constitucional en 1858 de una especie de "federalismo moderado", en expresión de Ayala ${ }^{61}$ que hizo renacer y ampliar la autonomía de las provincias, lo que lógicamente se tradujo en el incremento de las facultades de las asambleas provinciales, circunstancia que, a juicio de Ruggeri, ${ }^{62}$ propició que los constituyentes temieran, no sin cierto fundamento, que tales asambleas invadieran competencias propias del poder nacional; es en este contexto en el que debe entreverse la última ratio de la atribución a la Corte Suprema de la facultad de conservar incólume el pacto constituyente.

A tal efecto, la Constitución de 1858 estableció por vez primera, en forma expresa, el control judicial objetivo de la constitucionalidad, a través del instrumento procesal de la acción popular, atribuyendo a la Corte Suprema competencia para declarar la nulidad de los actos legislativos sancionados por las legislaturas provinciales, a petición de cualquier ciudadano, cuando fueren contrarios a la Constitución. Se instauraba de esta forma una acción judicial por vía principal, abierta a su presentación por cualquier ciudadano y de la que había de conocer en exclusiva la Corte Suprema, teniendo por objeto único los actos legislativos provinciales.

De lo establecido por la Constitución venezolana de 1858 bien cabe concluir que la misma es pionera en la consagración del control jurisdiccional concentrado de la constitucionalidad de las leyes, control que aunque no va a corresponder a un órgano $a d h o c$, a un órgano especializado, sí se va a concentrar en un sólo órgano, la Corte Suprema, que lo va a monopolizar. ${ }^{63}$

Aunque con muy diferentes vicisitudes, la acción popular ha sido una constante de buena parte de la historia constitucional venezolana, evolucionando progresivamente en el sentido de ampliar el objeto de con-

61 Carlos M. Ayala Corao. "Algunas consideraciones...», Op. Cit, p. 246.

62 Pablo Ruggeri Parra. La supremacía de la Constitución y su defensa (Jurisprudencia del Alto Tribunal Venezolano. 1840-1940), Caracas, 1941, p. 30.

63 Cfr. al efecto, Allan R. Brewer-Carías: «El control concentrado de la constitucionalidad de las leyes" (Estudio de Derecho Comparado), Cuadernos de la Cátedra Fundacional Allan R. Brewer-Carías de Derecho Público, Núm. 2 (Universidad Católica del Táchira), Caracas, Editorial Jurídica Venezolana, 1994, p. 16. 
trol, llegando a abarcar todos los actos del Estado. Ello no obstante, esas diversas vicisitudes por las que ha atravesado este instrumento procesal constitucional, han dado pie a algún sector de la doctrina ${ }^{64}$ a entender que el sistema institucionalizado por la Constitución de 1858, no obstante su utilidad, tuvo vida efímera.

Lo cierto será que la Constitución sancionada el 28 de marzo de 1864, que consolidó la estructura federal del Estado, vino a invertir los términos de la Carta de 1858, estableciendo un sistema de protección de la autonomía y los derechos de los Estados integrantes de la Federación, frente a los actos del Congreso Nacional y del propio Ejecutivo nacional. A ello se unió la eliminación de la acción popular, situación que se mantendría inalterable hasta 1893.

La Constitución venezolana de 1893 tendrá una notable trascendencia de futuro. En ella ha situado Brewer-Carías ${ }^{65}$ el punto de partida del sistema actualmente vigente en Venezuela, si bien es fácil intuir que por poco tiempo a la vista de las primeras decisiones de la Asamblea Constituyente elegida en 1999, de control concentrado de la constitucionalidad de los actos estatales. La Constitución de 1893, en efecto, atribuyó a la Alta Corte Federal competencia para: «Declarar cuál sea la ley, decreto o resolución vigente cuando estén en colisión las nacionales entre sí, o éstas con las de los Estados, o las de los mismos Estados, o cualquiera con esta Constitución».

El sistema de 1893, con la sola excepción de un breve período de tres años, entre 1901 y 1904, se ha mantenido en los textos constitucionales ulteriores, siendo seguido por el establecimiento, cuatro años más tarde, por intermedio del Código de Procedimiento Civil de 14 de mayo de 1897, del control difuso de la constitucionalidad, al establecer una suerte de poder-deber de los jueces de acordar la desaplicación de las leyes inconstitucionales al caso concreto sujeto a su decisión.

El control difuso sería ratificado constitucionalmente por la Carta Política de 1901, que vino además a complementarlo con la posibilidad que a los jueces concedía de someter a consulta de la Corte Suprema la cuestión de constitucionalidad, facultad que sería eliminada por la

64 José Guillermo Andueza Acuña. La Jurisdicción Constitucional en el Derecho Venezolano, Universidad Central de Venezuela, Caracas, 1974, p. 46.

65 Allan R. Brewer-Carías. El control de la constitucionalidad de los actos estatales, Caracas, Editorial Jurídica Venezolana, 1977, p. 27. 
Constitución de 1904. En cualquier caso, y a juicio de la mejor doctrina, ${ }^{66}$ Venezuela siempre ha tenido, conforme al modelo norteamericano, un sistema difuso de justicia constitucional.

En definitiva, en 1893 reaparecerá en Venezuela el instituto de la acción popular de inconstitucionalidad, que coexistirá desde 1897 con el control difuso, propiciando el primer modelo mixto, concentrado y difuso, de control de la constitucionalidad.

\section{El monopolio por la Corte Suprema del control judicial de constitucionalidad y el nacimiento del primer Tribunal Constitu- cional}

El modelo de acción popular colombo-venezolana de mediados del pasado siglo fortalecería extraordinariamente el rol de la Corte Suprema de Justicia como "guardián de la Constitución", quizá uno de los rasgos peculiares de América Latina durante una larga etapa de su accidentada historia constitucional, como ha significado Grant. ${ }^{67} \mathrm{Y}$ así, si en los Estados Unidos, y en forma similar en México, se concedía a la Corte Suprema o a sus salas un aspecto limitado de jurisdicción original, buen número de países latinoamericanos se iban a situar en el extremo radicalmente contrapuesto.

Sin pretender en modo alguno ser exhaustivo, cabría recordar que en Bolivia un Decreto Ley de 31 de diciembre de 1857, relativo a la organización judicial, incorporaba una atribución de la Corte Suprema que perfilaba a ésta, según Urcullo, ${ }^{68}$ como el órgano de control de la constitucionalidad, al habilitarla para conocer de las causas civiles de puro derecho, cualquiera que fuere su cuantía, cuando su decisión dependiera únicamente de la constitucionalidad de las leyes.

La Constitución Política de 1861 incorporaría en su Art. 65.2a la anterior atribución al asignar a la Corte de Casación el conocimiento

66 Allan R. Brewer-Carías: "La Justicia Constitucional en Venezuela", en el colectivo, Modernas tendencias del Derecho Constitucional en España y América Latina, Bogotá, Universidad Externado de Colombia, 1986, pp. 527 y ss.; en concreto, p. 537.

67 James Allan Clifford Grant. El control jurisdiccional de la constitucionaldiad de las leyes, Op. Cit., p. 78.

68 Jaime Urcullo Reyes. El control constitucional en Bolivia antes de 1994 [...] ", $O p$. Cit., p. 47. 
de «los negocios de puro derecho, cuya decisión dependa de la constitucionalidad o inconstitucionalidad de las leyes, atribución que Trigo $^{69}$ consideraría de enorme trascendencia al introducir en el sistema constitucional boliviano eel contralor jurisdiccional de la constitucionalidad de leyes y decretos a cargo de la Corte Suprema, máxima expresión del Poder Judicial».

Esta atribución de la Corte Suprema de Bolivia se mantendría en idénticos términos en las constituciones de 1868 y 1871 . Y otro tanto cabe decir de la Compilación de las Leyes del Procedimiento Civil, de 20 de febrero de 1878, que atribuía a la Corte Suprema el «conocer en única instancia de los asuntos de puro derecho, cuya decisión dependa de la constitucionalidad de las leyes». La Constitución de 1878 adicionaría, junto a las leyes, la referencia a los decretos y a cualquier género de resoluciones, previsión que sería reiterada por la Constitución de 1880, en vigor hasta 1938.

La Corte Suprema boliviana interpretaría la facultad comentada en el sentido de que le concedía jurisdicción «solamente cuando los interesados recusan de inconstitucionalidad la ley por la que debe decidirse su litigio". Resultaba, pues, indispensable la existencia de un caso particular concreto en el que debiera aplicarse o no la ley tachada de inconstitucionalidad. ${ }^{70}$

Ya hemos tenido oportunidad de referirnos al caso del Ecuador. La Constitución de 1869 configuró un control jurisdiccional de carácter preventivo, control que se activaba cuando el Presidente de la República se negaba a sancionar un proyecto de ley por considerarlo inconstitucional, supuesto en el que la Corte Suprema había de declarar si el proyecto era o no contradictorio con la norma suprema.

La Constitución de 1878 reiteraría esa modalidad de control que, sin embargo, se eliminará en las constituciones ulteriores (con las dos únicas salvedades de las cartas de 1929 y 1945), deduciéndose de ello, a juicio de Salgado Pesantes ${ }^{71}$, que los constituyentes ecuatorianos no dieron a ese control previo la debida importancia o, con criterios políícos, prefirieron dejar en manos del Ejecutivo dicho control.

69 Ciro Félix Trigo. Las Constituciones de Bolivia, Op. Cit., p. 97.

70 Observaciones de la Corte Suprema al Senado, del 24 de agosto de 1884, al Proyecto de Ley sobre queja e inconstitucionalidad, publicado en: Corte Suprema de Justicia de Bolivia. Jurisprudencia y doctrina expuestas en correspondencia y circulares de sus presidentes. Homenaje en el primer centenario, Sucre, 1927, p. 48. Cit. Por J.A.C. Grant: «El control jurisdiccional...», Op. Cit., p. 79. 
El protagonismo monopolista de la Corte Suprema sería especialmente intenso en Panamá, cuya segunda Constitución, fechada en 1941, inspirándose en la reforma constitucional colombiana de 1910, confió a la Corte Suprema la guarda de la integridad de la Constitución, atribuyendo a la misma "decidir definitivamente sobre la constitucionalidad de todas las leyes, decretos, ordenanzas y resoluciones denunciados ante ella como inconstitucionales por cualquier ciudadano, con audiencia del Procurador General de la Nación». Lógicamente, los efectos de las sentencias de la Corte Suprema declaratorias de la inconstitucionalidad se proyectaban con carácter general, esto es, eran efectos erga omnes.

La Constitución hoy vigente en Panamá, de 1983, en la misma dirección, establece, a juicio de la doctrina ${ }^{72}$, las bases de uno de los sistemas más concentrados, excluyentes y amplios de control de la constitucionalidad que existen en el Derecho comparado, al atribuir a la Corte Suprema de Justicia el poder exclusivo para conocer y decidir sobre la inconstitucionalidad de todos los actos estatales.

También en la República Oriental del Uruguay la Corte Suprema asumió un rol semejante, entrado ya el segundo tercio del presente siglo. La Constitución de 1934 asignó a la Corte Suprema de Justicia el conocimiento y resolución originario y exclusivo en cuanto a la posibilidad de declarar la inconstitucionalidad de las leyes.

Durante toda la vigencia de la Carta de 1934 la Suprema Corte de Justicia afirmó en su jurisprudencia que se requería un proceso judicial contradictorio, criterio que, según Gros Espiell, ${ }^{73}$ se atenía estrictamente al texto y que, pese a su carácter restrictivo, resultaba correcto, bien que el mismo autor considerara deseable una futura modificación de la norma constitucional que hiciera posible la aplicación de una fórmula más amplia y liberal en cuanto a la posibilidad de interponer el recurso de inconstitucionalidad.

71 Hernán Salgado Pesantes: «El control de constitucionalidad en la Carta Política del Ecuador", Op. Cit., p. 169.

72 Allan R. Brewer-Carías: «El sistema panameño de control concentrado de la constitucionalidad en el derecho comparadon, en el colectivo, El nuevo Derecho Constitucional Latinoamericano, Vol. II, Caracas, Asociación Venezolana de Derecho Constitucional - Konrad Adenauer Stiftung, 1996, pp. 889 y ss.; en concreto, pp. 893.

73 Héctor Gros Espiell: "La Jurisdicción Constitucional en el Uruguay», $O_{p}$. Cit., pp. 75-76. 
En lo que ahora importa, la Constitución uruguaya de 1942 las normas anteriores. Pero durante su vigencia, en 1949, la Corte Suprema de Justicia cambió su jurisprudencia respecto a su requerimiento de un proceso judicial contradictorio para que se pudiera plantear por las partes, por vía de excepción, la inconstitucionalidad de la ley. A partir de entonces, la Corte Suprema entendió que bastaba que hubiera un procedimiento judicial, que podía no ser contradictorio, para que fuera factible pedir en él la inconstitucionalidad de la norma.

La Constitución que entró en vigor el $1^{\circ}$ de marzo de 1952 sería decisiva en la materia que nos interesa, por cuanto, como advierte Esteva, ${ }^{74}$ esta norma vino a estructurar el sistema hoy vigente en el Uruguay. La finalidad de la reforma constitucional de 1952 era la de liberalizar, facilitar y extender todo lo relativo al recurso de inconstitucionalidad. ${ }^{75}$ Como consecuencia de la reforma se posibilitó que el recurso fuera interpuesto no sólo por vía de excepción, sino también por vía de acción; y así, lo que antes era una facultad de las partes en un proceso contradictorio, pasó a ser un derecho de todo aquel que se considerara lesionado en un interés directo, personal o legítimo. Y en cuanto al planteamiento de la excepción, se constitucionalizó lo que, como antes dijimos, ya era jurisprudencia de la Corte Suprema, esto es, que la excepción pudiera formularse en cualquier procedimiento judicial y no sólo en un juicio contradictorio.

La vigente Constitución de la República Oriental del Uruguay, de 1967, ha mantenido en la Corte Suprema el monopolio de la declaratoria de inconstitucionalidad. De acuerdo con la misma, reformada plebiscitariamente en 1989, 1994 y 1996, la declaratoria de inconstitucionalidad de una ley y la inaplicabilidad de las disposiciones afectadas por vicio de inconstitucionalidad, podrán solicitarse por todo aquel que se considere lesionado en su interés directo, personal y legítimo: 1) Por vía de acción, que deberá entablar ante la Suprema Corte de Justicia. 2) Por vía de excepción, que podrá oponer en cualquier procedimiento judi-

74 Eduardo G. Esteva Gallicchio: "La Jurisdicción Constitucional en Uruguay», en D. García Belaunde y F. Fernández Segado (coords.), La Jurisdicción Constitucional en Iberoamérica, Madrid, Dykinson - Ediciones Jurídicas - Editorial Jurídica Venezolana - Editorial Jurídica E. Esteva, 1997, pp. 897 y s.; en concreto, p. 904.

75 Héctor Gros Espiell: «La Jurisdicción Constitucional en el Uruguay», Op. Cit., p. 78. 
cial. Asimismo, el Juez o Tribunal que entendiere en cualquier procedimiento judicial, o el Tribunal de lo Contencioso-Administrativo, en su caso, también podrá solicitar de oficio la declaración de inconstitucionalidad de una ley y su inaplicabilidad antes de dictar resolución.

El fallo de la Suprema Corte que declara la constitucionalidad o inconstitucionalidad -y, en este supuesto, la inaplicabilidad de las disposiciones afectadas- se refiere exclusivamente al caso concreto y sólo tiene efecto en los procedimientos en que se haya pronunciado. ${ }^{76}$

Apegado al modelo uruguayo se sitúa el existente en Honduras desde la Constitución de 1982, que opta por un control de constitucionalidad que se concentra en la Corte Suprema de Justicia, a la que corresponde (Art. 1840) la resolución originaria y exclusiva en la materia, pudiendo ser instada su intervención por quien se considere lesionado en su interés directo, personal y legítimo, por vía de acción o por vía incidental.

Especialísima relevancia iba a tener este monopolio del control de constitucionalidad por la Corte Suprema en el último país del que vamos a ocuparnos, Cuba.

La primera Constitución de la República de Cuba, de 1901, en el punto cuarto de su Art. $83^{\circ}$, atribuía al Tribunal Supremo la decisión sobre la constitucionalidad de las leyes, decretos y reglamentos, cuando fuere objeto de controversias entre partes. Merino Brito ${ }^{77}$ destaca al efecto que los constituyentes cubanos, tanto en la elaboración de sus proyectos particulares como en el definitivo de Constitución, tuvieron como modelo la de los Estados Unidos de Norteamérica, cuyas instituciones fundamentales incorporaron al orden constitucional cubano. Sin embargo, en el punto que analizamos, la realidad revela que cada constituyente tuvo un concepto muy distinto de lo que habían de ser las controversias de inconstitucionalidad, como el propio autor anterior

76 Bien es verdad que, como recuerda Esteva, la reforma constitucional de 1994 agregó a las Disposiciones Transitoria y Especiales de la Carta un nuevo precepto en el que se disponía que se había de declarar la inconstitucionalidad de toda modificación de seguridad social, seguros sociales y previsión social contenidas en leyes presupuestales o de rendición de cuentas, a partir del $1^{\circ}$ de octubre de 1992. La Suprema Corte de Justicia, de oficio o a petición de cualquier habitante de la República, había de pronunciarse sin más trámite, indicando las normas a las que había de aplicarse esta declaración, que dejarían de producir efecto con carácter general. Eduardo Esteva Gallicchio: «La Jurisdicción Constitucional...”, Op. Cit., p. 916.

77 Eloy G. Merino Brito. El recurso de inconstitucionalidad y su jurisprudencia, La Habana, Cultural S.A., 1938, p. 10. 
reconoce y resulta claro si se atiende a las distintas fórmulas jurídicas esgrimidas al respecto en los diferentes proyectos particulares de Constitución presentados por algunos constituyentes, fórmulas que en algunos casos (así, por ejemplo, la vertebrada en el proyecto de don Leopoldo Berriel) eran inequívocamente tributarias de las existentes en otros países latinoamericanos, como Colombia y Venezuela. ${ }^{78}$

Esta mixtura de influjos quizá explique que la propia Comisión redactora, como reconoce la doctrina, ${ }^{79}$ tuviera dos criterios en cuanto a la significación y alcance del precepto del numeral cuarto del Art. $83^{\circ}$ : uno al redactarlo y otro después cuando, puesto a votación, se pidió por algún asambleísta aclaración del mismo. Cuando se redactó el inciso cuarto no se mencionó la palabra «recurso", pero cuando se pide la referida aclaración el ya citado don Leopoldo Berriel, hablando en nombre de la Comisión redactora, se referirá expresamente al «recurso que podrá utilizarse ante el Tribunal Supremo, que tendrá un carácter especial y en su día desenvolverá la ley procesal». Esta última interpretación, como es obvio, desbordaba el modelo norteamericano de la judicial review para ubicarse más bien en la dirección seguida por otros países latinoamericanos.

A partir de aquí no debe extrañar que la Ley de 31 de marzo de 1903, que desarrolló procesalmente el Art. 83.4 de la Constitución, estableciendo el procedimiento a seguir en las controversias entre partes sobre la constitucionalidad de una ley, decreto o reglamento, contemplara dos formas distintas para el planteamiento de la controversia de inconstitucionalidad: $1^{\text {a }}$ por vía de casación, cuando se tratara de actuaciones judiciales, y; $2^{a}$ por vía directa, en los demás casos.

Alegada la inconstitucionalidad de una norma en el curso de un procedimiento judicial, el juez o tribunal llamado a fallar en el juicio civil, criminal o contencioso-administrativo, debería abstenerse de dictar resolución sobre ese extremo, consignándolo así en la sentencia, y pudiendo las partes interponer un recurso de casación o apelación ante el Tribunal Supremo, fundándolo en la citada inconstitucionalidad. En realidad, este recurso de inconstitucionalidad era un recurso de casación por infracción de ley constitucional.

78 Crf. al efecto, Eloy G. Merino Brito. «El recurso de inconstitucionalidad [...] ", $O p$. Cit., pp. 11-13.

79 Eloy G. Merino Brito. «El recurso de inconstitucionalidad [...] », Op. Cit. pp. 1415. 
Sin embargo, como ya hemos dicho, junto a la vía de casación la Ley de 1903 contempla la vía directa, esto es, al margen de cualquier controversia judicial. El Art. $8^{\circ}$ de la citada norma legal facultaba a toda persona a la que se aplicara, fuera de actuaciones judiciales, una ley, decreto o reglamento que estimara inconstitucional, para ejercer el derecho de manifestarlo por escrito, dentro de los cinco días siguientes a la notificación, a la autoridad o funcionario que hubiera aplicado la norma en cuestión, anunciándole su intención de acudir al Tribunal Supremo de Justicia ara que decidiera la controversia.

La declaratoria de inconstitucionalidad, por el Tribunal Supremo, de la disposición legal o reglamentaria aplicada en la resolución impugnada implicaba la nulidad de esta última.

La Ley Constitucional de 3 de febrero de 1934 iba a dejar subsistente el recurso de parte afectada creado en 1903, modificando los efectos de la declaración de inconstitucionalidad en el sentido de impedir la ulterior aplicación de la ley objeto de esa declaratoria.

Asimismo, junto a esta acción o recurso iba a crear dos acciones públicas: una, ejercitable en cualquier momento por número de, al menos, veinticinco ciudadanos; otra, ejercitable también en todo tiempo, por la que un solo ciudadano estaba facultado para pedir la invalidación de cualquier ley que disminuyera, restringiera o adulterara los derechos garantizados constitucionalmente. De esta forma, bien puede afirmarse que la acción pública de inconstitucionalidad se convertía en realidad en Cuba en 1934.

Una nueva Ley Constitucional de 11 de junio de 1935 mantuvo casi sin alteración los preceptos que en este ámbito material había establecido la Ley de 1934.

Merino, ${ }^{80}$ haciendo balance estadístico, revela que entre 1934 y 1937, el Tribunal Supremo cubano dictó nada menos que 271 sentencias de inconstitucionalidad en Sala Plena, lo que es bien revelador del impacto público que tuvieron estos instrumentos procesales constitucionales.

En este marco, la Constitución promulgada en La Habana el 5 de julio de $1940^{81}$ iba a dar un paso adelante en esta materia de especialísima trascendencia de futuro. 
La novedad consistía en la creación dentro del Tribunal Supremo de Justicia, como una Sala integrante del mismo, de un Tribunal de Garantías Constitucionales y Sociales, Sala que cuando conociera de asuntos constitucionales estaría presidida por el Presidente del Tribunal Supremo e integrada, al menos, por quince magistrados.

Aunque orgánicamente integrado en el Tribunal Supremo, no nos cabe la menor duda acerca de la caracterización que mejor define a este Tribunal, que no es otra que la de un Tribunal Constitucional. Varios argumentos pueden aducirse en apoyo de esta tesis.

Formalmente, la Constitución, dentro del título décimocuarto, referente al Poder Judicial, dedica una sección al Tribunal Supremo de Justicia y otra al Tribunal de Garantías Constitucionales y Sociales. Por otro lado, éste fue objeto de regulación separada por intermedio de la Ley del Tribunal de Garantías Constitucionales y Sociales, de 31 de mayo de 1949, quedando al margen, por consiguiente, de la Ley Orgánica del Poder Judicial, todo lo cual es bien revelador de que no se quiso conformar este órgano como una Sala más del Tribunal Supremo. Hasta su propio nombre, inspirado en el Tribunal de Garantías Constitucionales de la Constitución Española de 1931, un auténtico Tribunal Constitucional, es bien revelador de la pretensión de los constituyentes cubanos al configurar este órgano.

Materialmente, aunque el Art. $174^{\circ}, \mathrm{d} / \mathrm{de}$ la Constitución de 1940 atribuye al Tribunal Supremo «decidir sobre la constitucionalidad de las leyes, decretos-leyes, decretos, reglamentos, acuerdos, órdenes, disposiciones y otros actos de cualquier organismo, autoridad o funcionarion, lo cierto es que esta competencia es asumida en su integridad por el Tribunal de Garantías Constitucionales, como muestra el Art. $182^{\circ}$ de la misma Constitución y corrobora su Ley reguladora.

En efecto, el Art. $2^{\circ}$ de la Ley de 1949, del Tribunal de Garantías, atribuye a éste el conocimiento de todos los asuntos constitucionales (y sociales), y el Art. $1^{\circ}$ (que adiciona un nuevo precepto, con el número 127-bis, a la Ley Orgánica del Poder Judicial), entre las atribuciones concretas del Tribunal, contempla la de conocer de los recursos de inconstitucionalidad contra las resoluciones, acuerdos, disposiciones, autos o sentencias que dicten el Pleno del Tribunal Supremo, su Sala de Go-

81 Puede verse el texto de la Constitución en Colección legislativa Cubana, Vol. II, $6^{\mathrm{a}}$ ed., La Habana, Jesús Montero editor, 1955. 
bierno ordinaria, su Sala de Gobierno especial -creada por el Art. $181^{\circ}$ de la Constitución (encargada de cuanto se refiere a los nombramientos, ascensos, traslados [...] ) - o cualesquiera de sus salas (Civil, Criminal y de lo Contencioso-administrativo). Es decir, la última palabra en cuanto se refiere a la conformidad de las actuaciones de los distintos poderes del Estado con la Constitución la tenía no el Tribunal Supremo, sino el Tribunal de Garantías Constitucionales.

Orgánicamente, el Tribunal de Garantías quedaba integrado, de acuerdo con el Art. $3^{\circ}$ de su propia Ley, por un Presidente, con categoría de Presidente de Sala del Tribunal Supremo, y ocho magistrados, con categoría de Magistrados del Tribunal Supremo, y nombrados de acuerdo con el procedimiento previsto para la designación de magistrados del Supremo por el Art. 180 de la Constitución: nombramiento por el Presidente de la República de entre una terna propuesta por un colegio electoral ad hoc de nueve miembros. El nombramiento debía ser sometido a la aprobación del Senado. Quiere ello decir que los miembros del Tribunal de Garantías eran elegidos con tal carácter específico. Bien es verdad que, como ya adelantamos, cuando el Tribunal conociera de asuntos constitucionales, había de quedar integrado por quince magistrados presididos por quien lo fuera del Tribunal Supremo, lo que entrañaba que se incorporaran al Tribunal, además del Presidente del Supremo, otros seis magistrados del mismo. Con todo, hay un cierto deslinde orgánico entre los magistrados del Tribunal de Garantías y los del Supremo, algo que se manifiesta incluso en la propia dicción de algunos preceptos de la Ley de $1949 .{ }^{82}$

El Tribunal de Garantías era competente para conocer, entre otros asuntos:

a) Los recursos de inconstitucionalidad contra leyes, decretos leyes, decretos, resoluciones o actos que negaran, disminuyeran, restringieran o adulteraran los derechos y garantías consignados en la Constitución o que impidieran el libre funcionamiento de los órganos del Estado.

82 Valga como ejemplo la redacción que el Art. $9^{\circ}$ de la Ley de 1949 da al Art. 60\%, párrafo último, de la Ley Orgánica del Poder Judicial: «Los nombramientos de Magistrados del Tribunal Supremo de Justicia y los que integren el Tribunal de Garantías Constitucionales y Sociales, deberán ser sometidos a la aprobación del Senadom. 
La Ley del Tribunal de Garantías, en la misma línea que la Ley Constitucional de 1934, habilitaba a veinticinco ciudadanos cubanos para la presentación de un recurso de inconstitucionalidad contra una norma objeto del mismo dentro del término de un año a contar desde la fecha de su promulgación. Si la inconstitucionalidad viniere motivada porque la norma en cuestión negara, disminuyera, restringiera, o adulterara los derechos o garantías constitucionales, la habilitación se hacía extensiva a cualquier persona mayor de edad y con plena capacidad civil, asimismo dentro del término de un año a contar desde la promulgación de la norma.

Si la norma impidiere el libre funcionamiento de los órganos del Estado, la habilitación se expandía a los miembros de cada uno de los órganos del Estado, en función de cual fuere el órgano impedido.

Las sentencias dictadas por el Tribunal de Garantías que estimaran un recurso de inconstitucionalidad dejaban sin efecto la aplicación de la disposición o regulación general o singular, obligando al órgano, autoridad o funcionario que hubiere dictado la disposición anulada por inconstitucional, a derogarla inmediatamente. En todo caso, y un tanto contradictoriamente con la anterior previsión, la Ley determinaba que la disposición legislativa o reglamentaria o medida declarada inconstitucional se había de considerar nula y sin valor, ni efecto, desde el día de la publicación de la Sentencia en los estrados del Tribunal (en los diez días siguientes a la fecha en que fuere dictada, la Sentencia había de publicarse en la Gaceta Oficial).

Si la declaración de inconstitucionalidad fuere por razones formales, la Sentencia había de anular con efectos pro futuro la totalidad de la ley, decreto ley, decreto, reglamento, acto o medida impugnada.

b) Las consultas de jueces y tribunales sobre la constitucionalidad de las leyes, decretos-leyes y demás disposiciones que hubieren de aplicar en juicio y respecto de las cuales estimaran que violan algunos de los preceptos de la Constitución que estatuyen garantías o reconocen derechos genéricamente. La consulta, que no podía versar sobre los preceptos constitucionales de aplicación inmediata, debía formalizarse a través de un auto, que no podía ser objeto de impugnación alguna.

El Tribunal de Garantías evacuaría las consultas por medio de un dictamen, en el que había de pronunciarse sobre la constitucionalidad o inconstitucionalidad del precepto consultado. 
c) Las cuestiones constitucionales promovidas por acción privada al margen de una actuación judicial.

La persona a quien se aplicare, al margen de una actuación judicial, una ley o norma de carácter general que estimare inconstitucional, tendrá el derecho de solicitar por escrito, dentro de los cinco días siguientes a la notificación, que la autoridad o funcionario que hubiere aplicado la norma, expida un testimonio literal de la resolución en cuya virtud se ha procedido, manifestando en el mismo escrito que tiene el propósito de interponer el correspondiente recurso de inconstitucionalidad.

La autoridad o funcionario ante quien se hubiere hecho la solicitud referida, habrá de entregar al solicitante, dentro de los tres días siguientes, el testimonio literal solicitado, emplazándolo para que, en el término de diez o quince días (según la provincia de que se tratara) a contar desde la entrega del testimonio, el solicitante comparezca ante el Tribunal de Garantías Constitucionales.

Presentado el recurso, el Tribunal había de resolver sobre su admisión. Admitido el recurso y tras la celebración de la vista, se dictaría sentencia en la que se había de resolver sobre el fondo de la reclamación.

d) La validez del procedimiento y de la reforma constitucionales. El Art. 66 de la Ley de 1949, en desarrollo de la Constitución, preveía la presentación de recurso de inconstitucionalidad contra las infracciones de las reglas constitucionalmente contempladas para la validez del procedimiento de reforma constitucional. Estimada la inconstitucionalidad, el Tribunal había de precisar, en cada caso, los efectos retroactivos de la nulidad declarada, así como si había o no de continuarse la tramitación del procedimiento de reforma.

En definitiva, muchos son los argumentos, como se ha podido ver, que permiten concluir que estamos ante un órgano que más bien responde a los rasgos propios de los tribunales constitucionales o, si acaso, a los de las actuales salas constitucionales autónomas existentes en algunos países como es el caso de Costa Rica, que a los de una sala especializada más del Tribunal Supremo.

Es más, en su jurisprudencia ${ }^{83}$ el Tribunal de Garantías tuvo oportu-

83 Crf. Al efecto, Mario Nin y Abarca: «El recurso de inconstitucionalidad en la Cons- 
nidad de subrayar su rol prácticamente equivalente, en su propio ámbito de competencia, al del Pleno del Tribunal Supremo. ${ }^{84}$

El protagonismo asumido en algunos países por la Corte Suprema de Justicia iba a terminar propiciando, en Cuba, el desgajamiento del seno del Tribunal Supremo de un órgano que, a nuestro juicio, ha de ser considerado como el primer Tribunal Constitucional latinoamericano.

La vigencia de la Constitución de 1940 no sería muy dilatada, pues ya antes incluso de la Revolución castrista, iba a ser sustituída por otra norma fundamental: la Ley Constitucional sancionada por Fulgencio Batista el 4 de abril de 1952. Esta Ley Constitucional no afectaría, sin embargo, al Tribunal de Garantías Constitucionales y Sociales, que quedaría perfilado en términos idénticos a como ya lo había sido en 1940 .

\section{Los primeros tribunales constitucionales latinoamericanos (1945- 1979)}

I. Finalizada la Segunda Guerra Mundial, el nuevo constitucionalismo que se expande por Europa y en el que ocupan un destacadísimo lugar los tribunales constitucionales, iba a impactar en América Latina. Primero, como señala Fix-Zamudio, de manera incipiente, pero en los últimos ańos con mayor vigor, sin que además ello supusiese afectar esencialmente la tradición «americana», es decir, sin que se hubiese producido su incompatibilidad con la desaplicación de las disposiciones legislativas por los jueces ordinarios, o en su caso, por la Corte Suprema, contrariamente a lo que ocurrió en el continente europeo. ${ }^{85}$

titución de 1940", en: Revista Cubana de Derecho, año XV Núm. 4, La Habana, octubrediciembre 1941, pp. 485 y ss.

84 En su Sentencia No 60, de 12 de mayo de 1941, dictada por el Tribunal Supremo en materia de inconstitucionalidad, al no existir aún el Tribunal de Garantías Constitucionales, se afirma: "Que la Sala de Garantías Constitucionales, por crear, no ha de ofrecer lógicamente menores garantías que el actual Pleno, pues, prácticamente, a un verdadero Pleno equivale si se tiene en cuenta que la preside de modo necesario, cuando conozca de asuntos constitucionales, el Presidente del Tribunal, sin que pueda estar integrada por menos de quince Magistrados, quorum mínimo legal exigido para el actual Pleno».

85 Héctor Fix-Zamudio: “Algunas tendencias predominantes en el constitucionalismo latinoamericano contemporáneon, en Ricardo Combellas (coord.), El nuevo Derecho Constitucional Latinoamericano, COPRE-CIEDLA-Konrad Adenauer Stiftung-Asociación Venezolana de Derecho Constitucional, Caracas, 1996, Vol. I, pp. 41 y ss.; en concreto, p. 47. 
El desarrollo de los tribunales constitucionales se inició en el Ecuador, ${ }^{86}$ siguiendo sucesivas experiencias en Guatemala (1965), Chile (1970) y el Perú (1979), país este último en donde el influjo español en la conformación del Tribunal de Garantías Constitucionales, será patente.

Las dos últimas décadas han supuesto una verdadera eclosión de tribunales constitucionales en América Latina, generándose modelos de jurisdicción constitucional novedosos. Parece fuera de toda duda que la funcionalidad mostrada por los tribunales constitucionales en Europa en general, y en España en particular, en orden a la consolidación de Estados de Derecho asentados en valores materiales, entre los que los derechos y libertades ocupan un primigenio papel, ha tenido mucho que ver con la eclosión a que antes aludíamos.

Nos ocuparemos ahora, muy brevemente, de los que bien podríamos considerar primeros modelos de tribunales constitucionales latinoamericanos o modelos históricos, pues ya no está ninguno de ellos en vigor.

II. La Constitución de Ecuador de 1945 es la primera (omisión hecha de Cuba) que crea un Tribunal de Garantías Constitucionales bajo el influjo directo, aunque muy sesgado, de la Constitución Española de 1931, como reconoce la mejor doctrina. ${ }^{87}$

Este Tribunal no sólo disponía de escasas competencias, sino que su intervención no era decisoria, correspondiendo esa decisión al Congreso y habiendo de limitarse el Tribunal a acordar la suspensión provisional de una norma legal cuando, a petición de un juez o tribunal de última instancia, el Tribunal de Garantías considerase que, efectivamente, la norma legal era contraria a la Constitución, supuesto en el que había de suspender la vigencia de la norma hasta que el Congreso se pronunciase acerca de la inconstitucionalidad reclamada. Ello significaba que el control estaba en manos del Legislativo y, por lo mismo, se trataba más bien de un control político.

Ello no obstante, hay que admitir que en 1945 se intenta en Ecuador buscar un nuevo modelo de justicia constitucional, pues no de otro modo ha de entenderse la creación del Tribunal de Garantías Consti-

86 Fix-Zamudio (Ibídem, p. 48) es de la opinión de que este desarrollo se inicia en Guatemala, quizá por la desnaturalizaciópn del modelo creado en Ecuador en 1945.

87 Hernán Salgado Pesantes: "El control de constitucionalidad...”, Op. Cit. p. 171. 
tucionales, que aunque con atribuciones disímiles, sentará el germen de una institución que reverdecerá periódicamente en ese país.

La escasísima vigencia de la Constitución de 1945, sustituída por otra de 31 de diciembre de 1946, supuso que el experimento ecuatoriano tuviera una efímera vida, pues la Carta de 1946 prescindió del Tribunal y, en sintonía con otras constituciones precedentes, encomendó al Consejo de Estado el control de la constitucionalidad.

La Constitución de 1967 iba, sin embargo, a reincorporar al Tribunal, bien que con atribuciones aún más reducidas, frente a las ya escasas de 1945. Y así, el Tribunal perdió su facultad de suspender provisionalmente las leyes inconstitucionales, que pasó a ser una atribución de la Corte Suprema de Justicia.

En 1945 se había atribuido al Tribunal la facultad de ejercer una suerte de control preventivo sobre los proyectos de leyes, cuando fueren objetados por el Presidente de la República y el Congreso no encontrare fundadas las objeciones presidenciales. En este supuesto, el Tribunal de Garantías tenía la última palabra en el Código de 1945. En la Constitución de 1967 el Tribunal se vería también privado de esta facultad.

De esta forma, como advierte Salgado, ${ }^{88}$ el control de la constitucionalidad quedo transformado en el Ecuador en un control disperso que era ejercido, en unos casos, por el Tribunal de Garantías Constitucionales, en otros, por la Corte Suprema de Justicia; y, en no pocas veces, por el propio Presidente de la República.

La Constitución ecuatoriana aprobada en referéndum de 15 de enero de 1978 vino nuevamente a establecer la figura del Tribunal de Garantías Constitucionales. Sin embargo, las sucesivas reformas de 1983, 1992 y 1996, sufridas por la citada Constitución, y que han afectado de modo notable al órgano que nos ocupa, creemos que sitúan el estudio del mismo, con más propiedad, en el último período (el que abarca los dos últimos decenios del siglo) y no en el que ahora abordamos.

III. Guatemala ha sido el tercer país, en un puro orden cronológico, en crear un órgano de estas características.

En Guatemala, la Constitución liberal de 1879, de larga vigencia en el país, tras su reforma de 1921, adoptaría por primera vez a nivel

88 Hernán Salgado Pesantes: «El control de constitucionalidad en la Carta Política del Ecuadors, $O p$. cit., p. 172. 
constitucional el sistema de control judicial de la constitucionalidad (bien que no puedan olvidarse los sugestivos antecedentes de 1837), al habilitar al Poder Judicial para declarar la inaplicación de cualquier ley o disposición de los demás poderes cuando fuere contraria a la Constitución. Las reformas de marzo de 1921 daban paso a la Constitución Federal de setiembre del mismo año, que posibilitaba la presentación ante la Corte Suprema de Justicia de un recurso de inconstitucionalidad contra una ley que se refiera a asuntos no ventilados ante los tribunales, recurso para cuya presentación se hallaba legitimada toda persona a quien dicha norma legal perjudicara en sus legítimos derechos, por su aplicación en un caso concreto. La Constitución de 1945 mantuvo la dirección fijada en esta materia un cuarto de siglo antes, habilitando a los tribunales de la jurisdicción ordinaria y al de lo contenciosoadministrativo para declarar en casos concretos y por sentencia de primera, segunda instancia y casación, la inaplicación de cualquier ley o disposición de los órganos que ejerzan funciones del poder público, cuando fueren contrarias a la Constitución.

Sería, no obstante, la Constitución de 15 de setiembre de 1965, la que introduciría un sesgo radicalmente novedoso en cuanto se refiere al control de constitucionalidad, al establecer un sistema mixto, por calificarlo con más propiedad de dual, que conjugaba la tradición del control judicial difuso norteamericano con la instauración de una Corte de Constitucionalidad que asumía un control de la constitucionalidad en vía principal y con una declaratoria de inconstitucionalidad con efectos erga omnes o generales. ${ }^{89}$

La propia Asamblea Constituyente de la República de Guatemala, que había aprobado la Constitución de 1965, decretaba la llamada Ley de Amparo, Hábeas Corpus y de Constitucionalidad, de 20 de abril de 1966.

La Carta de 1965 consagra de modo inequívoco la supremacía constitucional al disponer que los tribunales de justicia debían observar siempre el principio de que la Constitución prevalece sobre cualquier ley o tratado internacional, norma que se complementará con la declaración de nulidad ipso iure de las leyes o disposiciones de cualquier orden que, de un lado, violaran o tergiversaran los mandatos constitucionales, y de otro

89 Cfr. al efecto, Jorge Mario García Laguardia: «La defensa de la Constitución», $O p$. cit., pp. 55-79. 
lado, regularan el ejercicio de los derechos constitucionalmente garantizados, disminuyéndolos, restringiéndolos o tergiversándolos.

La Constitución (Art. 246\%) acogía, entre las atribuciones generales de los órganos del Poder Judicial, el control difuso o incidental, al prever que en casos concretos, en cualquier instancia y en casación, antes de dictar sentencia, las partes podían plantear la inconstitucionalidad total o parcial de una ley, debiendo el tribunal pronunciarse al respecto, ${ }^{90}$ en el bien entendido de que si se declarase la inconstitucionalidad, la sentencia había de limitarse a establecer que el precepto legal era inaplicable al caso planteado, siendo transcrita dicha sentencia al Congreso y quedando obligado el Ministerio Público a interponer recurso de apelación o, en su caso, de casación, contra la sentencia que declare la inconstitucionalidad.

La sentencia que admitiera la inconstitucionalidad era declarativa, esto es, establecía una nulidad preexistente con efectos retroactivos (ex tunc), generando efectos tan sólo respecto del caso concreto en que fuere dictada (inter partes).

Junto a esta modalidad de control en el caso concreto, la Carta de 1965 acogía un control concentrado, principal (no incidental) y de efectos erga omnes, control que, como ya adelantamos, se encomienda a un órgano no permanente, pues se había de integrar cuando se presentara una acción: la Corte de Constitucionalidad.

La Corte de Constitucionalidad, verdadero Tribunal Constitucional quizá, en rigor, el primer órgano autónomo de esta naturaleza en América Latina, por cuanto que el Tribunal de Garantías cubano, orgánicamente, se vertebraba como una Sala del Tribunal Supremo, y el Tribunal ecuatoriano no se acomodaba, funcionalmente, al rol de un órgano de esta naturaleza, quedaba integrada por doce miembros, cuatro de ellos designados por la Corte Suprema de Justicia, y los restantes por sorteo realizado por la propia Corte Suprema, entre los magistrados de la Corte de Apelaciones y los del Tribunal de lo Contencioso-administrativo. La presidencia de la Corte de Constitucionalidad recaía en el presidente

90 El Decreto No 8 de la Asamblea Constituyente, por el que se decretaba la Ley Constitucional de Amparo, Hábeas Corpus y de Constitucionalidad, establecía dos vías procedimentales para controlar la inconstitucionalidad de las leyes en casos concretos: la vía de acción y la de excepción. Por lo demás, su Art. $102^{\circ}$ disponía que la inconstitucionalidad como acción o excepción será siempre resuelta como punto de derecho, y sobre ella no podrá rendirse prueba. 
de la Corte Suprema de Justicia, tal y como disponía el Art. $105^{\circ}$ de la Ley ya varias veces citada.

La Corte de Constitucionalidad era competente para conocer de los recursos de inconstitucionalidad interpuestos contra las leyes o disposiciones gubernativas de carácter general viciadas total o parcialmente de inconstitucionalidad.

Se hallaban legitimados para interponer un recurso de inconstitucionalidad: el Consejo de Estado, órgano que presidía el Vicepresidente de la República; el Colegio de Abogados, por decisión de su asamblea general; el Ministerio Público, por disposición del Presidente de la República tomada en Consejo de Ministros, y cualquier persona o entidad a quien afecte directamente la inconstitucionalidad de una ley o disposición gubernativa impugnada, con el auxilio de diez abogados en ejercicio.

El Ministerio Público era siempre parte, correspondiéndole la legitimación pasiva, estando obligado a realizar la defensa de la constitucionalidad de la norma impugnada, bien que también le era factible mostrarse de acuerdo con la impugnación.

La Corte de Constitucionalidad podía decretar la suspensión de la ley o disposición gubernativa, si la inconstitucionalidad fuere notoria y susceptible de causas gravámenes irreparables. Para decretar la suspensión se requería del voto favorable de la mayoría absoluta de los miembros de la Corte.

La sentencia estimatoria de la inconstitucionalidad requería del voto favorable de ocho de los doce miembros de la Corte, esto es, de dos tercios de los mismos, pudiendo declarar la inconstitucionalidad total o parcial de la ley o norma de carácter general impugnada. Fix-Zamudio, con evidente razón, se manifestaría críticamente frente al elevado quorum de votos necesarios para la declaratoria de inconstitucionalidad. ${ }^{91}$

La sentencia estimatoria de la Corte, a juicio de García Laguardia, ${ }^{92}$ tenía efectos semiconstitutivos, calificación que respondía al hecho de que en el caso de que decretara la suspensión provisional, sus efectos eran ex tunc, pues venía a establecer una suerte de nulidad preexistente en forma retroactiva, mientras que en los demás casos la sentencia era constituriva, siendo sus efectos ex nunc. De conformidad con el Art. $108^{\circ} \mathrm{de}$

91 Héctor Fix-Zamudio. Los tribunales constitucionales y los derechos humanos, México, Instituto de Investigaciones Jurídicas, UNAM, 1980, pp. 141-142.

92 Jorge Mario García Laguardia. La defensa de la Constitución, Op. Cit., p. 60. 
la varias veces citada Ley de 1966, de Amparo, Hábeas Corpus y de Constitucionalidad, "cuando la sentencia declare la inconstitucionalidad total de una ley o disposición gubernativa de carácter general, ésta quedará sin vigor, y si la inconstitucionalidad fuere parcial quedará sin vigor en la parte declarada inconstitucional. En ambos casos dejará de surtir efecto desde el día siguiente al de la publicación del fallo en el Diario Oficial». Obviamente, contra las sentencias dictadas por la Corte de Constitucionalidad no cabía recurso alguno.

La experiencia de la Corte guatemalteca fue corta, como la de la propia Carta Política de 1965: de 1966 a 1981, esto es, quince años escasamente, pero, según una vez más García Laguardia, ${ }^{93}$ fue fructífera. En ese lapso conoció de muy pocos casos. El Consejo de Estado y el Colegio de Abogados, sorprendentemente, no hicieron uso de su capacidad para recurrir ante la Corte; el Presidente de la República sólo lo hizo una sola vez (por cierto, el único recurso estimado por la Corte de Constitucionalidad mediante su Sentencia de 8 de enero de 1971) y los demás recursos de que tuvo oportunidad de conocer la Corte fueron obra de particulares. La experiencia vino a demostrar en Guatemala que el tantas veces esgrimido peligro del "gobierno de los jueces", o lo que es igual, de la politización del Tribunal, de la actuación de la Corte como un órgano político, no se evidenció. ${ }^{94}$

El golpe de Estado de 23 de marzo de 1982 declaró en suspenso la Constitución de 1965. Ello supuso lógicamente el final de la Corte de Constitucionalidad. Sin embargo, ésta dejó una semilla que iba a fructificar muy poco tiempo después, al iniciarse, bajo tutela castrense, un nuevo proceso de transición hacia la democracia que culminaba en las elecciones constituyentes celebradas el $1^{\circ}$ de julio de 1984, fruto de las cuales sería la Asamblea Constituyente que elaboró la Constitución hoy vigente, sancionada el 31 de mayo de 1985, en la que reaparecería la institución que nos ocupa.

93 Ibidem, pp. 74-75.

94 Jorge Mario García Laguardia (en «La Corte de Constitucionalidad (Tribunal Constitucional) de Guatemala. Orígenes y Competencias", en: Cuadernos Constitucionales México-Centroamérica, Núm. 8, México, Instituto de Investigaciones Jurídicas de la UNAM-Corte de Constitucionalidad de la República de Guatemala, 1994, pp. 38-39) considera que las causas esenciales por las que la Corte satisfizo las expectativas creadas en torno a su rol, fueron: su integración específicamente judicial, su carácter de tribunal circunstancial y la restringida legitimación para accionar. 
IV. Chile es el país que, cronológicamente, sigue en lo que se refiere a la institucionalización de un Tribunal Constitucional.

Quizá convenga recordar, con carácter previo, que en 1925 una Comisión plural designada por el entonces Presidente de la República, Arturo Alessandri, preparaba una Constitución que iba a ser aprobada plebiscitariamente en agosto de 1925 , sustituyendo a la casi ya centenaria de 1933. La Constitución de 1925 rigió en Chile hasta el 11 de setiembre de 1973, fecha del sanguinario golpe de Estado pinochetista.

Grant $^{95}$ ha subrayado cómo en 1925, en Chile, se hicieron notables esfuerzos para conformar un monopolio por parte de la Corte Suprema de Justicia en orden al control de la constitucionalidad.

Como ya tuvimos oportunidad de indicar, la Constitución de 1925 estableció por vez primera en Chile el control judicial de la constitucionalidad de las leyes, que se canalizó por intermedio del llamado recurso de inaplicabilidad, configurado como una atribución exclusiva de la Corte Suprema de Justicia, que podía interponerse en cualquier estado del juicio ordinario, sin suspender su tramitación, de acuerdo con el procedimiento establecido por el Auto Acordado de la propia Corte Suprema de 22 de marzo de 1925. El recurso de inaplicabilidad venía a delimitar un control concentrado de constitucionalidad y con efectos inter partes.

Como recuerda Nogueira, ${ }^{6}$ la Corte Suprema, durante la vigencia de la Constitución de 1925, se negó sistemáticamente en los recursos de inaplicabilidad que le fueron sometidos a su consideración y fallo, a conocer y fallar acerca de los vicios formales de las leyes producidos en su proceso de formación, esto es, acerca de los vicios formales de inconstitucionalidad generados en el procedimiento legislativo, reduciendo su competencia tan sólo a conocer y fallar los recursos de inaplicabilidad de las leyes por vicios materiales o de fondo, afirmándose en la doctrina de la separación de poderes, a modo de justificación de su discutible posición.

La interconexión de los poderes Legislativo y Ejecutivo se iba a acentuar en Chile, como en tantos otros países en la misma época,

95 James Allan Clifford Grant. El control jurisdiccional de la constitucionalidad de las leyes, Op. cit., p. 85.

96 Humberto Nogueira Alcalá: «El Tribunal Constitucional chileno», en el colectivo, Una mirada a los Tribunales Constitucionales. Las experiencias recientes, Op. cit., pp. 111 y ss.; en concreto, p. 112. 
como una suerte de variante más de la lucha entre un Ejecutivo que trata paulatinamente de adquirir mayor poder en el ámbito de la actividad legislativa, y un Congreso que no sólo defiende sus posiciones, sino que pretende avasallar las del Ejecutivo, invadiéndolas ostensiblemente en ocasiones al autoasignarse diversos cometidos propios de la Administración. En esta situación, no ha de extrañar que, como dice Silva Cimma, ${ }^{97}$ se produjera una crisis de juridicidad en el sistema del derecho chileno. Había conciencia de la crisis y, en muchos casos, la convicción de que el Congreso era el que mayoritariamente excedía de sus atribuciones.

Es por ello por lo que comenzó a abrirse paso en círculos políticos la necesidad de crear un órgano que asumiera el rol de dilucidar los conflictos jurídicos que se suscitaran como consecuencia de la aprobación de leyes supuestamente inconstitucionales. Los numerosos conflictos constitucionales entre quienes, con roles distintos era de hecho colegisladores, exigían no postergar la creación de un órgano jurisdiccional ad hoc que pudiera darles solución.

Con el tiempo, como recuerda Nogueira, ${ }^{98}$ se desarrolló una conciencia política acerca de la necesidad de establecer un órgano jurisdiccional especializado que pudiera hacer realmente efectivo el principio de supremacía constitucional en el proceso de formación de los preceptos legales, además de entregarle algunas competencias de control de constitucionalidad de los tratados internacionales sometidos a la aprobación del Congreso y de resolver acerca de los vicios en que pudiera incurrir el Presidente de la República en materia de promulgación de las leyes.

La reforma constitucional de 1970 vino así a marcar un hito en el camino de paulatina evolución y perfeccionamiento de las instituciones políticas chilenas. ${ }^{99}$

Ya el Presidente Frei había presentado en julio de 1965 una indicación al Congreso para crear un Tribunal Constitucional integrado por nueve miembros. El 17 de enero de 1969 el propio Presidente Frei entregó un nuevo proyecto en cuyo mensaje de fundamentos podía

97 Enrique Silva Cimma. El Tribunal Constitucional de Chile (1971-1973), Caracas, Editorial Jurídica Venezolana, 1977, pp. 14-15.

98 Humberto Nogueira Alcalá. El Tribunal Constitucional chileno, Op. Cit., p. 112.

99 Enrique Silva Cimma. El Tribunal Constitucional de Chile, Op. Cit., p. 24. 100 Teodoro Ribera Neumann. Función y composición del Tribunal Constitucional de Chile, Op. Cit., p. 37. 
leerse lo que sigue: «[...] El proyecto en trámite consulta la creación del Tribunal Constitucional, encargado de dirimir los conflictos cuya raíz consiste en una encontrada interpretación de la Carta Fundamental [...]. El Tribunal Constitucional que por este Mensaje propongo crear, ya existente en otras legislaciones más avanzadas, cumplirá satisfactoriamente su objetivo primordial, cual es la definición de los conflictos de poderes que surjan por la desigual interpretación de las normas constitucionales, cuyo imperio y observancia quedan así robustecidos».

Tras largas discusiones en el seno de ambas cámaras y diversas modificaciones introducidas frente a la iniciativa presidencial, era aprobada la Ley de Reforma de la Constitución, No 17284, de 23 de enero de 1970, por la que se creaba un Tribunal Constitucional.

El Tribunal, que, según se ha dicho, ${ }^{100}$ fue un producto de la tenacidad de la doctrina iuspublicista, nació con la animadversión de la Corte Suprema, algo, por lo demás, muy común en otros países, Corte que rechazaba la participación de sus miembros en el nuevo órgano.

El Tribunal Constitucional chileno se constituyó el 10 de setiembre de 1971 y a través de sus Autos Acordados publicados en el Diario Oficial los días 23 de noviembre y 11 de diciembre de 1971, el propio Tribunal aprobó los estatutos jurídicos sobre su organización, funcionamiento, régimen de su personal y procedimiento aplicable.

El Tribunal se hallaba compuesto por cinco ministros que habían de permanecer en ejercicio de sus funciones por un período de cuatro años, pudiendo ser reelegidos. Tres de ellos eran designados por el Presidente de la República con acuerdo del Senado y los dos restantes por la Corte Suprema de Justicia de entre sus miembros. Como señalara quien fuera Presidente del Tribunal, Enrique Silva Cimma, ${ }^{101}$ la generación del Tribunal era y debía ser fundamentalmente apolítica, lo que no quería decir que sus miembros carecieran de una posición ideológica.

Los años de funcionamiento del Tribunal coincidieron con la división del país en dos bandos irreconciliables. Al Tribunal le fue difícil permanecer ajeno a tales avatares, tanto más cuanto su gestión se vinculaba a problemas de enorme trascendencia política. Todo ello, como admite Silva Cimma, ${ }^{102}$ contribuyó a crear una imagen irreal de politización en torno al Tribunal, imputación que quien fuera su Presidente rebate como por entero falsa.

101 Enrique Silva Cimma. El Tribunal Constitucional de Chile, Op. Cit., p. 45.

102 Ibidem, p. 55. 
Entre las atribuciones de mayor interés del Tribunal chileno, cabe recordar ahora: a) la resolución de las cuestiones sobre constitucionalidad que se suscitaran durante la tramitación de los proyectos de ley y de los tratados internacionales sometidos a la aprobación del Congreso; b) la resolución de las reclamaciones en el caso de que el Presidente de la República no promulgara una ley cuando debiera hacerlo; c) la resolución de las cuestiones que se suscitaran sobre la constitucionalidad de un decreto con fuerza de ley; y, d) la resolución de las contiendas de competencia que determinaran las leyes.

Aún existiendo otras atribuciones del Tribunal de índole menor, las expuestas ya son lo suficientemente reveladoras de algo que ya se ha señalado con reiteración: los conflictos entre el Legislativo y el Ejecutivo, entre el Congreso y el Presidente, producidos con ocasión de la tramitación parlamentaria de los proyectos de ley, son la última ratio explicativa de la aparición del Tribunal. ${ }^{103}$

Señalemos con algo más de detalle que se hallaban legitimados para plantear una cuestión sobre constitucionalidad suscitada con ocasión de la tramitación de un proyecto de ley, el Presidente de la República, cualquiera de las dos cámaras o más de un tercio de sus miembros, debiendo de formularse la cuestión antes de la promulgación de la ley. El Tribunal disponía de diez días para resolver, contados desde que recibiera el requerimiento, que en ningún caso suspendía la tramitación del proyecto.

A su vez, estaban legitimados para impugnar por inconstitucionalidad un decreto con fuerza de ley, el Presidente de la República, dentro del plazo de los treinta días siguientes al rechazo por la Contraloría, por causa de inconstitucionalidad, de un decreto con fuerza de ley. Cualquiera de las cámaras o más de un tercio de sus miembros se hallaban también legitimados.

Las sentencias del Tribunal Constitucional tenían fuerza de "cosa juzgada" y eran, por lo mismo, inimpugnables. Las disposiciones que el Tribunal declarara inconstitucionales no podían convertirse en ley en el proyecto impugnado o en el decreto con fuerza de ley. Por el contrario, la confirmación de la constitucionalidad de un precepto impugnado entrañaba, como consecuencia de futuro, que no pudiera ser declara-

103 Cfr. al efecto, Alejandro Silva Bascuñán: «El Tribunal Constitucional», en Eduardo Frei y otros, Reforma constitucional, 1970, Santiago, Editorial Jurídica de Chile, 1970, pp. 199-200. 
do inaplicable por el mismo vicio que fue materia de la Sentencia constitucional, por la Corte Suprema de Justicia.

El Tribunal ejerció sus funciones hasta el golpe de Estado pinochetista, acaecido el 11 de setiembre de 1973. La Junta de Gobierno militar puso fin a la efímera vida de este órgano por medio del Decreto Ley № 119 , de 10 de octubre de 1973. Pese a lo fugaz de su existencia, Nogueira ${ }^{104}$ subraya que existe consenso entre la doctrina chilena acerca de los buenos servicios rendidos por el Tribunal a la República. En todo caso, su corta vida no impidió la toma de conciencia en torno a la necesidad de ampliar sus competencias, en un futuro democrático, para hacer efectivo en plenitud el Estado de Derecho.

Contrasta con el rol cumplido por el Tribunal Constitucional, la función asumida por la Corte Suprema al hilo de su ejercicio del control constitucional "represivo" o a posteriori que le encomendaba, como ya dijimos, el inciso segundo del Art. $86^{\circ}$ de la Constitución de $1925 .^{105}$ A la Corte Suprema cabía ejercer una importante función de salvaguarda de la primacía constitucional y, sin embargo, como afirma Tapia Valdés, ${ }^{106}$ el examen de la forma en que la Corte cumplió su misión protectora de la supremacía constitucional deja una pobre impresión. Al revés de sus congéneres argentina y brasileña, a la Corte Suprema chilena le faltó vuelo intelectual, capacidad creadora y confianza institucional para enfrentarse a los titulares de los otros poderes del Estado. La Corte Suprema no ha sustentado doctrina alguna de significación para la vida jurídico-política del país, y ha respaldado de hecho expresa o tácitamente, los regímenes de facto que ha tenido Chile.

La Corte Suprema, en definitiva, ha soslayado o ignorado el hecho de que el Art. $86^{\circ}$ de la Constitución le otorgó una facultad general y amplia para declarar la inaplicabilidad de la ley en casos particulares, pues el recurso de inaplicabilidad que estableció el Art. 86 de la Carta de 1925

104 Humberto Nogueira Alcalá. El Tribunal Constitucional chileno, Op. Cit., p. 113.

105 A tenor del inciso segundo del Art. 86 de la Carta de 1925: «La Corte Suprema, en los casos particulares de que conozca o le fueren sometidos en recurso interpuesto en juicio que se siguiere ante otro tribunal, podrá declarar inaplicable, para ese caso, cualquier precepto legal contrario a la Constitución. Este recurso podrá deducirse en cualquier estado del juicio, sin que se suspenda su tramitación”.

106 Jorge Tapia Valdés: «Jurisdicción constitucional y gobiernos de facto. El caso de la Corte Suprema de Chilen, en el colectivo, La Jurisdicción Constitucional en Iberoamérica (Universidad Externado de Colombia), Op. Cit., pp. 243 y ss.; en concreto, p. 257. 
tenía carácter meramente subsidiario de la facultad permanente y general de que disponía la Corte para declarar por propia iniciativa, de oficio, la inaplicabilidad de una ley. El único objeto del recurso era permitir a la parte cuyo juicio pudiere no llegar al alto nivel jurisdiccional de la Corte Suprema por razón de competencia, plantear la cuestión de inaplicabilidad.

En resumen, la Constitución de 1925 otorgó a la Corte Suprema un papel activo y dinámico, como institución tutelar de la supremacía de la Constitución, profundamente diferenciado del rol pasivo que la Corte jugó dentro del sistema jurídico chileno. Y como afirma Tapia, ${ }^{107}$ sólo el peso de una tradición civilista y decimonónica puede explicar que la Corte jamás haya ejercido la facultad de declarar de oficio o por propia iniciativa, inaplicable una ley por entenderla contraria a la Constitución. Más aún, durante la vigencia de la Constitución de 1925, ni siquiera hizo uso de su facultad cuando se planteó la reclamación por la vía del recurso de casación, al entender, con una visión hiperformalista, que la tacha de inconstitucionalidad de la ley «sólo puede hacerse por medio del recurso de inaplicabilidad».

En este marco, se entiende que la aparición del Tribunal Constitucional en Chile significara algo así como una entrada de aire fresco purificador de un engranaje tan importante en un Estado de Derecho como es el de los mecanismos orientados a la salvaguarda de la primacía de la Constitución.

V. Perú es el último de los países que en el marco temporal acotado constitucionaliza un Tribunal de esta naturaleza, bajo el rótulo de Tribunal de Garantías Constitucionales, lo que acontece en la Constitución de 12 de julio de 1979, que en este punto sería objeto de desarrollo por intermedio de la Ley No 23385, Ley Orgánica del Tribunal de Garantías Constitucionales, norma, por cierto, bastante influida por la Ley Orgánica del Tribunal Constitucional español.

La Constitución del Perú, en la línea de la guatemalteca de 1965, crea una suerte de modelo dual de jurisdicción constitucional, en el que, a la par que el Tribunal de Garantías ejerce un control concentrado, los jueces y tribunales ordinarios llevan a cabo un control difuso. El Art. $236^{\circ}$ de la Constitución determinaba al efecto que «en caso de in- 
compatibilidad entre una norma constitucional y una legal ordinaria, el juez prefiere la primera».

Admitida la coexistencia de un control de constitucionalidad concentrado en el Tribunal de Garantías y de un control difuso, se planteaba una importante cuestión: jestaban vinculados los jueces y tribunales ordinarios por la jurisprudencia, por la doctrina constitucional, establecida por el Tribunal de Garantías Constitucionales? Parece incuestionable que allí donde existe un Tribunal de esta naturaleza, está llamado el mismo a ser el «intérprete supremo de la Constitución», como prevé la Ley Orgánica 2/1979, del Tribunal Constitucional español, y consiguientemente, su interpretación de la Constitución y del conjunto del ordenamiento se ha de imponer a los demás operadores jurídicos, jueces y tribunales ordinarios incluidos. La Ley Orgánica del Tribunal de Garantías del Perú obviaba esa calificación de intérprete supremo, que era sustituida por la de "órgano de control de la Constitución", genérica e inadecuada función que estaba llamado a cumplir el Tribunal peruano.

El Art. $39^{\circ}$ de la Ley Orgánica del Tribunal de Garantías Constitucionales, en su primer párrafo, determinaba que: «Los jueces no pueden dejar de aplicar una norma cuya inconstitucionalidad haya sido desestimada por el Tribunal». Ello parecía implicar una clara vinculación de los jueces y tribunales ordinarios a los fallos dictados por el Tribunal, pero no resolvía la cuestión fundamental: la vinculatoriedad de la interpretación jurisprudencial de la Constitución sentada por el Tribunal. De hecho, no siempre los órganos jurisdiccionales ordinarios atendieron la jurisprudencia constitucional del Tribunal de Garantías.

El Tribunal quedaba integrado por nueve miembros, tres de ellos designados por el Congreso, tres por el Poder Ejecutivo, y tres por la Corte Suprema de Justicia; se optaba así por una fórmula de equilibrio entre los tres poderes que nos parece, en principio, acertada. Los magistrados eran nombrados por un período de seis años, renovándose por tercios cada dos años.

La Constitución (Art. 297\%) exigía para acceder a la condición de miembro del Tribunal los mismos requisitos que para ser Vocal de la Corte Suprema y probada ejecutoria democrática y en defensa de los derechos humanos. El aspecto más controvertido era la edad mínima de 50 años exigida para el acceso como miembro del Tribunal, edad a todas luces excesiva. 
Una crítica generalizada entre algunos autores ${ }^{108}$ viene referida al estrecho margen de competencias previsto para el Tribunal, circunstancia a la que se uniría la limitada legitimación para accionar ante el Tribunal. Sin embargo, a nuestro modo de ver, la primera de las críticas es injustificada. De las tres Grundformen o formas fundamentales de la justicia constitucional: el control de normas, los recursos de amparo y los conflictos constitucionales, el Tribunal peruano asumía la competencia para conocer de las dos primeras. Y aunque no se contemplaba la acción popular de inconstitucionalidad, tampoco podía sostenerse, a nuestro entender, que la legitimación para interponer una acción de inconstitucionalidad era excesivamente estricta, pues estaban habilitados al respecto: el Presidente de la República; veinte senadores, es decir, un tercio del total; sesenta diputados, esto es, un tercio igualmente de los miembros de la Cámara; la Corte Suprema de Justicia, el Fiscal de la Nación y, finalmente, 50,000 ciudadanos.

La acción de inconstitucionalidad podía interponerse frente a leyes, decretos legislativos, normas regionales de carácter general y ordenanzas municipales. La Ley preveía un plazo muy amplio, seis años contados a partir de la publicación de la norma, para poder interponer una acción de inconstitucionalidad.

Quizá las mayores disfunciones del Tribunal provinieran, de un lado, de las determinaciones legales relativas al procedimiento, y de otro, de la propia actitud de quienes integraron este órgano.

Por una parte, el Art. $8^{\circ}$ de la Ley No $^{\circ} 23385$ exigía para resolver y adoptar acuerdos un mínimo de cinco votos conformes, salvo para la resolución de los casos de inconstitucionalidad o para la inadmisión de la acción. Supuestos en los que el mismo precepto exigía seis votos conformes sobre un total de nueve miembros del Tribunal. Con ello, la Ley no sólo dificultaba exageradamente la estimación de la inconstitucionalidad, sino que al exigir, con desafortunadísima redacción, seis votos conformes, en uno u otro sentido, para la resolución de los casos de inconstitucionalidad, vino de hecho a impedir el pronunciamiento del Tribunal. La realidad permite constatar que en el período que media entre 1983 y 1992, años de funcionamiento de este órgano,

108 Este es el caso, entre otros, de Carlos Cárdenas Quirós: «El Tribunal de Garantías Constitucionales y la Constitución Política del Perú de 1979", en Revista del Foro, Lima, Colegio de Abogados de Lima, julio-diciembre de 1981. 
de las quince acciones de inconstitucionalidad que conoció, en cinco oportunidades no se alcanzó el número de votos necesario para dictar sentencia, algo que resulta inconcebible.

A tan pobre balance contribuyeron, por otra parte, los propios integrantes del Tribunal. Escudados en las exigencias formales del Art. $8^{\circ}$ de su propia Ley Orgánica ${ }^{109}$, regidos en su interpretación por un hiperformalismo absolutamente alejado de lo que debe ser una interpretación valorativa, esto es, regida por los valores materiales de la Constitución, y carentes de la más elemental conciencia de que todo Tribunal viene obligado a dictar sentencia cada vez que a través de una acción es instado a ello por quien está dotado de legitimidad para recurrir, los magistrados del Tribunal de Garantías tuvieron buena parte de responsabilidad en el desprestigio en que se vio pronto inmerso este órgano. ${ }^{110}$

A todo lo inmediatamente antes expuesto se unió, como recuerda $\mathrm{Abad}^{111}$, un indebido apego de algunos de los magistrados a los órganos que los habían designado, el impacto de las influencias políticas, como también la debilidad frente a las presiones económicas y, finalmente, determinadas interpretaciones jurisprudenciales erróneas o de escaso contenido.

La resultante final de todo lo expuesto fue la más que decepcionante labor del Tribunal, muy particularmente en el ámbito del control normativo. ${ }^{12} \mathrm{Y}$ es curioso constatar que el primer fallo del Tribunal desató

109 Buen ejemplo de ello lo constituyen las tesis de uno de los magistrados, Manuel Aguirre Roca, en "Los fallos del Tribunal de Garantías Constitucionales ante la crítica», en: Thémis. Revista de Derecho, segunda época, año I, Núm. 3, pp. 20 y ss.

110 Aníbal Quiroga León, con buen criterio a nuestro juicio, llegó a señalar que la falta de los pronunciamientos requeridos por parte del Tribunal determinaba que sus miembros incurrieran en la responsabilidad funcional a que de alguna manera aludía el Art. 17.5 de su propia Ley Orgánica. Aníbal Quiroga León: «El Tribunal de Garantías Constitucionales ante el dilema de ser o no ser", en: Thémis. Revista de Derecho, segunda época, 1986, Núm. 4, pp. 40 y ss.

111 Samuel B. Abad Yupanqui: «La jurisdicción constitucional en la Carta Peruana de 1993: antecedentes, balance y perspectivas", en el colectivo Una mirada a los tribunales constitucionales. Las experiencias recientes, Op. Cit., pp. 191 y ss.; en concreto, p. 196.

112 De los quince pronunciamientos del Tribunal, en cinco procesos no se alcanzó el número de votos necesario para dictar sentencia; dos se resolvieron mediante autos de inadmisibildiad; en un tercer proceso, un extremo de la demanda fue resuelto, declarándose infundado, mientras que el otro no pudo serlo por no reunir los votos necesarios; hubo dos sentencias que declararon infundada la demanda, y otras cinco, por último, en que se declaró fundada la pretensión de inconstitucionalidad. 
los más elogiosos comentarios, ${ }^{113}$ abriendo notables expectativas que más tarde se iban a frustrar. El Tribunal pareció reactivarse durante el mandato presidencial de Fujimori, circunstancia que explica su clausura con ocasión del autogolpe de Estado de abril de 1992, a través del Decreto Ley No 25422.

El fracaso final del órgano en cuestión no impide destacar la extraordinaria relevancia de las innovaciones que en el ámbito del control normativo de constitucionalidad introdujo la Constitución de 1979. A partir de ella, el control concentrado coexistiría con el difuso. Bien es verdad que, declarada la inconstitucionalidad por el Tribunal, es decir, al hilo del control concentrado, tal declaratoria no conllevaba la nulidad inmediata de la norma, cuando se tratare de una ley, como es connatural en tal tipo de control. Había de ser el Congreso el que, dentro del plazo de 45 días había de aprobar una ley derogatoria de la norma legal inconstitucional. De no hacerlo así, el Art. $301^{\circ}$ de la Constitución determinaba de modo taxativo que había de entenderse derogada la norma inconstitucional. Esta fórmula traducía la preocupación por salvaguardar la primacía del Congreso en lo tocante a la dación de normas legislativas, que en la mente del constituyente peruano posiblemente se vería truncada de posibilitarse la derogación automática de la norma legal cuando mediara una sentencia declaratoria de la inconstitucionalidad. Sin embargo, la derogación ex constitutione, como consecuencia de una sentencia constitucional, no debe entenderse en modo alguno como un indicio de la subordinación del Congreso al Tribunal de Garantías, sino como una prueba de la primacía de la Constitución sobre todos los poderes públicos y, por lo mismo, sobre cualesquiera normas emanadas de ellos. Esta disfunción sería superada en la Carta de 1993.

113 Este es el caso de Domingo García Belaunde: «El primer fallo del Tribunal de Garantías Constitucionales», en Ius et Praxis, Núm. 4, 1984, pp. 115 y ss.; en concreto, p. 